\title{
A APRENDIZAGEM DE TÓPICOS DE CÁLCULO POR ALUNOS DE ENGENHARIA ATRAVÉS DO TRABALHO DE PROJETO
}

\author{
J. M. MAGALHÃES ${ }^{1}$ \\ Instituto Superior de Engenharia do Porto \\ jdm@isep.ipp.pt ${ }^{1}$
}

Artigo submetido em 19/04/2018 e aceito em 24/06/2019

DOI: $10.15628 /$ holos.2019.7218

\section{RESUMO}

Em algumas escolas de engenharia, a qualidade dos cursos é orientada por processos de ensino e aprendizagem assente no modelo CDIO e direcionada para a certificação EUR-ACE. Das várias normas CDIO, as experiências de elaboração de projetos em diferentes unidades curriculares proporcionam a realização de atividades em equipa a partir do 1. ano desses cursos. Com o intuito de avaliar o contributo de tarefas tipo PBL na aprendizagem de conteúdos matemáticos foi implementada uma experiência de ensino em dois cursos de licenciatura em engenharia baseada num projeto multidisciplinar. Num dos cursos, o projeto envolveu a construção de um modelo físico baseado no conceito de pêndulo e no outro curso o modelo físico foi o do pistão do motor de um automóvel. Com a realização destas atividades procuramos avaliar o contributo de tarefas tipo PBL na aprendizagem de conteúdos matemáticos em cursos de licenciatura em engenharia. Na procura de compreender o significado que os alunos dão à realização da tarefa PBL, adotamos uma abordagem de natureza qualitativa e interpretativa. Os dados foram recolhidos através dos relatórios escritos pelos alunos, das suas apresentações públicas e de uma entrevista. Na análise dos dados, apresentam-se as fases da elaboração da tarefa, as questões envolvidas, os objetivos a alcançar com a sua realização, os resultados obtidos pelos alunos e as suas perceções sobre a realização da PBL. Os resultados indiciam que os alunos reconhecem a utilidade da realização de projetos na sua formação académica e profissional futura. Conclui-se que há uma melhor gestão das tarefas PBL quando integradas em mais do que uma unidade curricular.

PALAVRAS-CHAVE: Ensino Superior, Licenciatura em Engenharia, Aprendizagem de tópicos de cálculo, Aprendizagem baseada em projetos.

\section{THE LEARNING OF CALCULUS TOPICS BY ENGINEERING STUDENTS THROUGH THE PROJECT WORK}

\begin{abstract}
In some engineering schools, the quality of the undergraduated degrees is guided by teaching and learning processes based on the CDIO model and directed towards the EUR-ACE certification. From the various CDIO norms, the experiences of designing projects in different courses provide the accomplishment of activities in group from the first year of those degrees. In order to evaluate the contribution of PBL tasks in the learning of mathematical contents, a teaching experience was implemented in two undergraduate degrees in engineering based on a multidisciplinary project. In one of the degrees, the project involved the construction of a physical model based on the pendulum concept and in the other degree the physical model was the piston of the motor of an automobile. With the accomplishment of these activities we try to evaluate the contribution of
\end{abstract}

tasks PBL type in the learning of mathematical contents in undergraduate degrees in engineering. In an attempt to understand the meaning that students give to the achievement of the PBL task, we adopt a qualitative and interpretative approach. The data were collected through reports written by the students, their public presentations and an interview. In the analysis of the data, the phases of the elaboration of the task, the questions involved, the objectives to be achieved with its accomplishment, the results obtained by the students and their perceptions about the realization of the PBL are presented. The results indicate that the students recognize the usefulness of the realization of projects in their future academic and professional formation. It is concluded that there is a better management of the PBL tasks when integrated in more than one course.

KEYWORDS: Higher education, Degree in Engineering, Learning of calculus topics, Project-based learning. 


\section{INTRODUÇÃO}

Os conteúdos matemáticos da área do cálculo integram os programas de unidades curriculares que, em geral, fazem parte do 1. ano dos cursos de Engenharia. Dos alunos que ingressam esses cursos dos Institutos Politécnicos são conhecidas as suas dificuldades na aprendizagem de conteúdos das unidades curriculares na área do cálculo (Ferreira, Nicola \& Figueiredo, 2011), o que tende a condicionar a assimilação de novos conceitos. Na procura de ultrapassar algumas dessas dificuldades, o docente que leciona as unidades curriculares de cálculo tem ao seu dispor uma panóplia de recursos tecnológicos que podem atenuar as inadaptações dos alunos. Compete ao professor que leciona nos cursos de Engenharia adotar estratégias que promovam a aprendizagem dos alunos na sua unidade curricular. Este estudo apresenta resultados de uma adaptação dos processos de aprendizagem na unidade curricular de Matemática I aos padrões de qualidade definida pela rede Europeia para a acreditação do ensino de engenharia EURACE (European Network for Accreditation of Engineering Education). O EURACE é uma marca de qualidade europeia para os programas de engenharia que incorpora os pontos de vista e perspetivas dos principais intervenientes - estudantes, instituições de ensino superior, empregadores, organizações profissionais e organismos de acreditação de qualidade - e foi estabelecido com o objetivo de aumentar a legibilidade e a transparência do ensino de engenharia.

Na unidade curricular de Matemática I promoveu-se uma metodologia de aprendizagem sustentada por alguns dos requisitos definidos no CDIO (Concept-Design-Implement-Operate) (Crawley, Malmqvist, Östlund \& Brodeu, 2007), nomeadamente a inclusão de atividades de resolução de problemas e de projetos integradores nas diversas áreas de engenharia e o trabalho cooperativo entre os alunos. A iniciativa CDIO, estrutura educacional já implementada em diversas escolas de todo o mundo, está em consonância com a aplicação de metodologias PBL (ProjectBased Learning) na formação dos alunos de engenharia. O modelo CDIO é uma ferramenta onde constam uma lista de conceitos, raciocínios associados e ferramentas de engenharia que servem de guia à formação de diplomados em engenharia. É um modelo que tenta auxiliar os engenheiros a trabalhar competências transversais e de inter-relações que incluam, para além dos aspetos técnicos, questões ambientais, sociais e éticas. Em 2004, o consórcio que gere o modelo de educação CDIO aprovou 12 normas para auxiliar a construção do Syllabus do CDIO. Entre essas normas destacam-se as que enfatizam a existência de atividades de projetos, normalmente, em unidades curriculares integradoras, a utilização de métodos inovadores e ativos conducentes a uma aprendizagem prática e integradora nas diversas unidades curriculares do curso e a existência de atividades de aprendizagem baseadas na resolução de problemas, com menos ênfase na transmissão passiva de informação. Nas normas do modelo CDIO considera-se aprendizagem ativa experimental quando os alunos assumem papéis de simulação da prática profissional da engenharia, o que se traduz na conceção e construção de projetos e na realização de simulações.

Tendo em conta que a atividade dos alunos depende da natureza das tarefas matemáticas que lhes são propostas, elaborou-se uma experiência de ensino em dois cursos de Engenharia que propiciou aos alunos a realização de uma tarefa interdisciplinar de Aprendizagem Baseada em Projeto (PBL) para a aprendizagem de conteúdos matemáticos de Matemática I. Este projeto envolveu a construção de um modelo físico baseado no conceito de pêndulo e do pistão do motor de um automóvel, a modelação matemática das duas situações e a construção de um simulador 
computacional dinâmico em GeoGebra. Com base nessas experiências, este estudo teve como objetivo avaliar o contributo de tarefas tipo PBL na aprendizagem de conteúdos matemáticos de alunos de cursos de licenciatura em engenharia. Na concretização deste objetivo procuramos identificar as atividades que os alunos realizam no desenvolvimento de um trabalho de projeto no âmbito da aprendizagem de tópicos de cálculo, as dificuldades que sentiram nessa realização e as perceções dos alunos sobre o contributo do trabalho de projeto na sua aprendizagem.

\section{APRENDIZAGEM BASEADA NO TRABALHO DE PROJETO}

Tomando como base as orientações estabelecidas para os cursos de Graduação em Engenharia e alinhando com as exigências impostas pela globalização, Masson, Miranda, Munhoz e Castanheira (2012) referem que "a formação do engenheiro deve ser generalista, humanista, crítica e reflexiva, que o capacite a absorver e desenvolver novas tecnologias, estimulando a sua atuação crítica e criativa na identificação e resolução de problemas" (pp. 1-2). Na perspetiva destes autores, o processo de formação do engenheiro deve contemplar uma formação integral que inclua a promoção da aquisição de conhecimentos de forma crescente, complexa e mutável, paralelamente com o desenvolvimento dos atributos profissionais. Uma das formas de promover estas características do futuro engenheiro é através da Aprendizagem Baseada em Projetos ou Project-Based Learning ( $\mathrm{PBL}$ ), que permite adquirir conhecimentos científicos e tecnológicos, incluindo questões ambientais e sociais; desenvolver capacidades de desenvolver projetos, resolver problemas, comunicar e de trabalhar em equipa (Crawley et al., 2011; Edström \& Kolmos, 2014; Lehmann, Christensen, Du \& Thrane, 2008; Masson et al., 2012). Esta metodologia de aprendizagem baseada em projetos tem origem no trabalho de Dewey, partindo da ideia 'aprender mediante o fazer', valorizando, questionando e contextualizando a capacidade de pensar dos alunos. A PBL é uma abordagem sistémica em que a aquisição de conhecimentos e competências dos alunos é feita por meio de um processo de investigação sobre problemas reais. Segundo Masson et al. (2012), as atividades de PBL, se forem bem planeadas em contexto educacional, permitem desenvolver uma aprendizagem em que os alunos são os agentes da produção do conhecimento. Essas atividades não seguem o padrão rígido e pré-estabelecido do ensino de conteúdos, mas permite que estes sejam incluídos estrategicamente durante o desenvolvimento do projeto. As metas e os conteúdos curriculares específicos são incorporados na gestão do projeto de modo a contribuir para o desenvolvimento das habilidades e de hábitos de aprendizagem contínua.

$\mathrm{Na} \mathrm{PBL}$, os projetos são a base para que os alunos consigam competências e relacionem as disciplinas entre si na análise e identificação de problemas, bem como o processo de resolução de problemas (Edström \& Kolmos, 2014). Nessa metodologia pretende-se que os alunos, de uma forma integrada e através da reflexão que fazem sobres as suas práticas, ganhem competências sobre processos, aprendizagem autónoma, gestão de projetos, colaboração, comunicação e construção de conhecimento colaborativo. Um princípio fundamental é que os alunos sejam responsáveis pelo seu processo de aprendizagem e o professor seja tutor, que oriente os alunos e que apresenta várias métodos e ferramentas de apoio à resposta de um problema. A PBL é uma estratégia de ensino e aprendizagem em que os alunos têm de resolver um problema complexo da vida real e que aprendem por pesquisa direta na resposta à tarefa que Ihes é proposta (Jurewitsch, 2012). 
Segundo Zuffi e Onuchic (2007), uma metodologia de ensino e aprendizagem baseada em problemas não consiste em resolver problemas de aplicação que, normalmente, aparecem nos manuais escolares no fim da apresentação de um conteúdo disciplinar. Pelo contrário, constituemse tarefas que podem ser apresentadas aos alunos antes da aprendizagem formal de um conteúdo, através de situações problemáticas, o mais perto possível do real, e que os desafiem a raciocinar sobre a necessidade de construir novos conceitos e processos, para além da utilização de conhecimentos prévios anteriormente adquiridos. Este tipo de atividades requer um amplo conhecimento, não só de técnicas e procedimentos, mas também das relações que existem entre si. No processo de aprendizagem baseada na resolução de problemas, compete ao professor apresentar tarefas para que o aluno seja capaz de compreender e identificar os dados de um problema, tomar decisões para o resolver, estabelecer relações, saber comunicar resultados e ser capaz de usar técnicas ou procedimentos conhecidos. Para que estes objetivos sejam cumpridos, o problema deverá ser qualquer situação que estimule o aluno a pensar, que lhe seja interessante e desafiador, mas não trivial, conhecido ou dentro do âmbito da sua realidade. A aprendizagem baseada na resolução de problemas é uma tendência expressa nas intenções dos programas de ensino em várias áreas do ensino superior e, em particular, na engenharia (Crawley, Malmqvist, Östlund \& Brodeu, 2007).

Os problemas são o ponto de partida para os processos de aprendizagem na metodologia PBL (Edström \& Kolmos, 2014; Graaff \& Kolmos, 2003). A escolha dos problemas depende dos objetivos de aprendizagem e exige problemas abertos, a menos que os objetivo a alcançar sejam mais específicos e aí o mais adequado serão problemas mais circunscritos. Estes devem ser abordados num contexto conhecido do aluno, analisados com base em teorias e resolvidos com métodos de resolução de problemas. Os problemas devem ser escolhidos de forma a produzir resultados de aprendizagem globais e interdisciplinares, permitir um nível de compreensão mais profundo e os resultados da aprendizagem devem ser transferíveis para situações semelhantes (Kolmos \& Graaff 2013). A aprendizagem é em equipa, ocorre através do diálogo e da comunicação. Os alunos aprendem uns com os outros, compartilham conhecimento e organizam o processo de aprendizagem colaborativa.

Com base em tais características, Masson et al. (2012) advogam que na aprendizagem baseada em PBL se deve considerar os seguintes pressupostos: (i) atender que compete aos alunos fazer as suas próprias escolhas, de acordo com os seus interesses; (ii) abranger a interdisciplinaridade e incluir assuntos da vida e da experiência do aluno; (iii) atender ao ritmo e ao estilo de aprendizagem do aluno; (iv) incluir materiais tecnológicos; (v) permitir a interação e a aprendizagem colaborativa; e (vi) ser capaz de disseminar processos e resultados. A escolha do tema do projeto é fundamental para a aplicação do PBL, que deve ser motivador e conduzir o estudante a novas descobertas. Este projeto deve ser minimamente abrangente aos conteúdos programáticos das unidades curriculares do curso. Para estes investigadores, durante o desenvolvimento de um projeto é necessário que o professor oriente, motive e desafie os alunos a fazerem parte de uma equipa. Para tal, os alunos e professor devem fazer uma gestão rigorosa do projeto que inclua cronogramas, estratégias para a solução das tarefas e para a avaliação dos resultados. Para Masson et al. (2012), o acompanhamento e avaliação do processo ensinoaprendizagem dos alunos, segundo a visão de PBL, devem estar em consonância com o sistema de avaliação e o Projeto Didático-Pedagógico do Curso, o que requer o compromisso institucional e um esforço dos gestores do curso. 
Para Campos (2012), a metodologia PBL é uma estratégia de aprendizagem ativa desenhada para cursos com uma nova visão educacional e que não fundamentem os seus currículos em disciplinas que apenas atribuem tarefas rotineiras ou de grau de dificuldade reduzida para os estudantes. Nesta metodologia, cada problema/projeto é um tema da realidade profissional do engenheiro e é integrado num conjunto de disciplinas, em que os alunos têm que trabalhar em equipa. A aprendizagem dá-se através de um problema/projeto de solução aberta, propiciador de diálogo entre os elementos do grupo. O grupo de alunos deve apresentar uma solução para o problema dentro de um prazo definido, que será composto por um protótipo e/ou um relatório. Posteriormente, os alunos mostram o que aprenderam em discussão com o professor sobre o 'produto' desenvolvido. As propostas educacionais baseadas na metodologia PBL, segundo Campos (2012), têm como objetivos gerais a contribuição para a formação integral dos alunos como seres humanos, fomentar a sua criatividade e empreendedorismo, formar profissionais de alta qualidade com moral, ética e com capacidade critica. Este tipo de metodologia ativa permite uma formação académica que integra atividades entre as escolas e as empresas.

Lima (2012) advoga que o PBL permite a transição de um sistema de ensino baseado na transmissão de conhecimentos para um sistema baseado no desenvolvimento de competências, em contextos específicos, académicos e/ou profissionais. Na engenharia, o autor refere que essas competências podem ser aquelas que estão definidas no programa EUR-ACE (Tabela 1).

Tabela 1: Competências definidas no Programa EUR-ACE (Lima, 2012, p. 8).

Conhecimento e Compreensão Ciências de base, complementares e de

Análise

Resolução de problemas de engenharia (definição; exploração; decisão; solução)

Desenho

Realização de projetos de engenharia

Investigação

Recolha e tratamento de informação em projetos de engenharia

Prática

Preocupações éticas, ambientais, sociais na prática de engenharia

Competências Transversais

Trabalho em equipa; comunicação [contextos (inter) nacionais]; ética profissional; autonomia; capacidade para aprender; liderança 
$\mathrm{Na}$ promoção de tais competências, muito contribuem, segundo Lima (2012), as caraterísticas da aprendizagem baseada em projetos tal como se apresenta na seguinte figura:

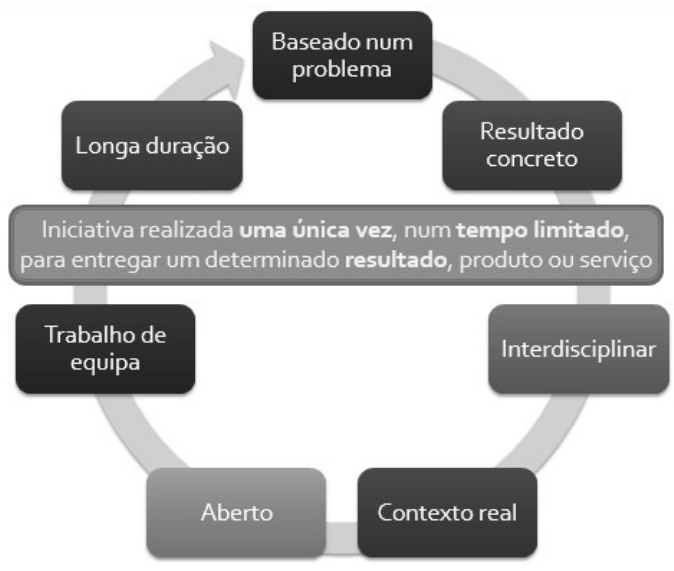

Figura 1: Características da aprendizagem baseada em projetos (Lima, 2012, p. 13).

A implementação deste tipo de metodologia implica que haja uma articulação na instituição de ensino ao nível da sua inserção nos currículos das diferentes disciplinas, do envolvimento dos alunos e dos professores segundo os princípios do PBL e das avaliações dos alunos, que se devem centrar nos processos colaborativos do projeto e no desenvolvimento de parcerias com agentes externos à escola.

Como proposta educativa, Lima (2012) apresentou um contexto onde a metodologia de aprendizagem baseada em projetos, de alunos do 1. - ano do curso de Mestrado Integrado em Engenharia e Gestão Industrial (MIEGI) de uma universidade portuguesa, seguiu as seguintes fases: Organização: identificação de temas e de recursos para o projeto; Preparação: definição e especificação do tema do projeto, da calendarização das atividades e do modelo de avaliação; Início: formação dos grupos e clarificação do que se pretende realizar; Execução: realização de diversas atividades, tais como a resolução de tarefas, elaboração de relatórios, reuniões tutoriais e feedback às equipes de acordo com o plano estabelecido; Finalização: compilação das notas do trabalho das equipas, preparação do workshop final para discutir o processo de aprendizagem.

$\mathrm{Na}$ consecução do seu estudo, Lima (2012) reuniu 113 relatórios finais dos alunos, 50 protótipos do 1. ano (Lego Mindstorms), mais de 300 apresentações de alunos e publicação de artigos dos alunos ( 7 relatórios em formato de artigo e 9 publicações em conferências internacionais). Em termos educativos, os resultados revelaram uma boa aceitação pelos estudantes do trabalho de projeto, como revela o comentário de um dos alunos: "Nas aulas aprendíamos os fundamentos teóricos e no projeto PBL conseguíamos efetuar diversas aplicações práticas desses fundamentos teóricos (...) esta aplicação da teoria em termos práticos contribuiu imenso para a nossa aprendizagem" (Lima, 2012, p. 32). Lima (2012) considera que o resultado global da implementação da metodologia de ensino e aprendizagem baseada em projetos num curso requer um compromisso entre todas as partes envolvidas no processo educativo. $\mathrm{O}$ autor considera, ainda, que não existe um modelo universal de implementação de metodologias de ensino que envolvam $\mathrm{PBL}$, porque os processos envolvidos estão em permanente evolução. 
Segundo Edström e Kolmos (2014), o PBL pode ser aplicado em diferentes contextos culturais, áreas temáticas e pode ser implementado a diferentes níveis no sistema educacional, numa unidade curricular ou num programa completo de um curso. Para os autores, os alunos sujeitos a uma metodologia PBL conseguem um nível mais alto de habilidades e competências, uma aprendizagem mais profunda e maior motivação para a frequência do curso ou unidade curricular. Ainda segundo os autores, o PBL como modelo de ensino e aprendizagem é compatível e sobrepõem-se com o modelo CDIO, embora este último seja um guia para o desenvolvimento de programas estruturados em engenharia. Estes dois modelos de educação na engenharia compartilham de um mesmo objetivo - a ênfase no desenvolvimento de habilidades profissionais através de processos de aprendizagem que são semelhantes à prática da vida real. No modelo CDIO, as atividades de aprendizagem têm como base os problemas/projetos e os alunos aprendem com práticas autênticas de engenharia. Para transformar essas experiências práticas em aprendizagem, os alunos devem ser continuamente guiados para usar reflexão e feedback, apoiando-os na avaliação do seu trabalho e na identificação de potenciais aprimoramentos de resultados e processos. Do ponto de vista do resultado da aprendizagem, os alunos devem apresentar soluções funcionais e testáveis dos seus projetos e, simultaneamente, desenvolver conhecimentos disciplinares e habilidades de engenharia profissional (Crawley et al., 2005, 2007). A avaliação e a classificação dos alunos devem refletir a qualidade dos resultados da aprendizagem, em vez do desempenho do produto em si. O princípio pedagógico é que a aprendizagem integrada exige avaliação integrada (Padrão CDIO 11) (Edström et al., 2005).

\section{SIMULAÇÃO E MODELAÇÃO MATEMÁTICA}

Na mesma linha da resolução de problemas, Bornatto (2002) defende que a realização de simulação e a modelação matemática proporcionam ao estudante um ambiente de aprendizagem em que a construção do conhecimento se dá a partir das ações do aprendente. Na aprendizagem matemática, a simulação é um suporte para 'fazer matemática' -- experimentar, visualizar múltiplas facetas, generalizar, conjeturar, manipular os conceitos abstratos de uma forma mais atraente e interativa -- que torna a Matemática mais atraente. Nas metodologias de ensino e aprendizagem com base na simulação e na modelação matemática os estudantes participam na escolha do tema a ser estudado e a visão da matemática é altamente interdisciplinar. Para Bornatto (2002), as simulações e modelações matemáticas revêem-se nas atividades de pesquisa matemática onde "o conhecimento é construído a partir de muita investigação e exploração, e a formalização é simplesmente o coroamento desse trabalho, que culmina na escrita formal e organizada dos resultados obtidos" (p.69). O conhecimento é construído pelo próprio aluno e não apenas memorizado, porque só assim será mobilizado e reconstruído mentalmente perante situações problema ou desafios com que se depara. Bornatto sugere que se devem explorar pedagogicamente as potencialidades das novas tecnologias, incluindo as simulações através da experimentação e da visualização, em que o computador deve ser encarado como sendo apenas um lápis mais rápido.

As simulações em computador são uma ferramenta adequada para deliberadamente criar conflitos cognitivos e para contrapor às conceções preexistentes nos alunos. Através de simulações os alunos têm a oportunidade de refletir sobre conceitos e resolver conflito conceptuais que existam nos seus conhecimentos (Rutten, 2014; Trundle \& Bell, 2010). Segundo Hennessy e outros (2007), para alunos que tenham mais dificuldades em aprendizagem, a visualização deve ser o foco 
principal para a compreensão dos fenómenos e de conceitos. A simulação permite que os alunos explorem modelos e processos de complexidade muito maior do que é possível em ambientes laboratoriais, sem perigos e com custos menores. A simulação é frequentemente apoiada num software que é facultado ao estudante e na modelação é o aluno quem escolhe o fenómeno, desenvolve o seu modelo e implementa-o nesse software. Para Bellemain, Bellemain e Gitirana (2006), elaborar uma simulação no computador implica, geralmente, programar um modelo dinâmico com as propriedades dos objetos ou dos fenómenos a observar e que posteriormente será visualizado no computador. No pondo de vista de reforço das aprendizagens dos alunos, a simulação de fenómenos com o computador pode ser abordada de duas formas: (a) $\mathrm{O}$ aluno investiga o fenómeno ou o objeto a aprender, atuando sobre um modelo que já foi previamente programado; (b) A partir da descrição do modelo do fenómeno, o aluno constrói a sua simulação num software. Na perspetiva destes autores, o uso de uma metodologia de aprendizagem apoiada na simulação permite que os alunos sejam capazes de construir modelos matemáticos a partir da exploração de comportamentos de objetos e fenómenos, o que favorece a construção dos conhecimentos.

A modelação matemática é definida por muitos autores (Bassanezi, 2002; Biembengut \& Hein, 2000; Blum, 2002; Galbraith et al., 2007) e como sendo um processo de construção de modelos que transforma uma situação real numa situação matemática, conforme o ciclo representado na Figura 2.

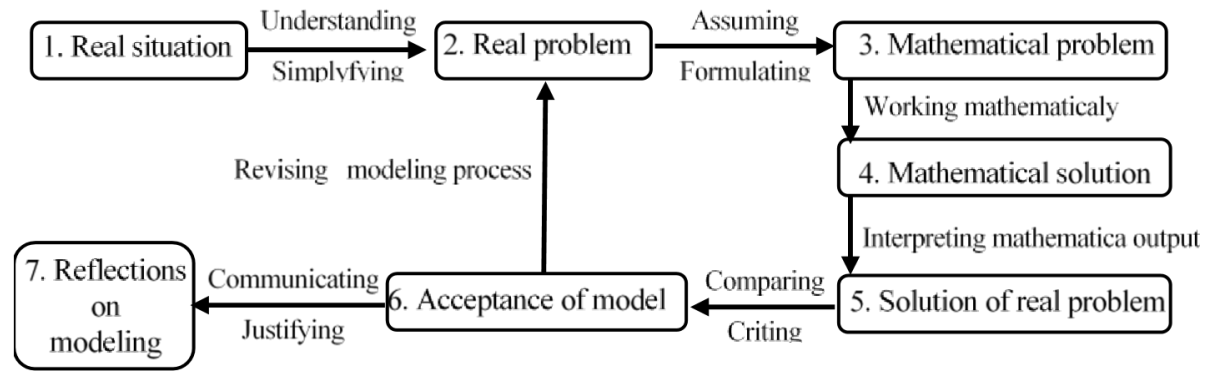

Figura 2: Ciclo de modelação matemática (Takaci \& Budinski, 2013, adaptado).

Este ciclo de modelação aparece frequentemente associado à matemática aplicada e é composto por várias fases: na primeira fase seleciona-se e define-se o problema que se quer estudar; na segunda fase escolhe-se uma estrutura matemática para representar o problema, nomeadamente procura-se quais são as suas variáveis e como se relacionam no problema; na terceira fase formula-se o problema como um problema matemático; na quarta fase resolve-se o problema anterior utilizando técnicas matemáticas necessárias para o efeito; resolvido o problema matemático, na quinta fase testa-se e interpreta-se a sua solução de modo a retirar conclusões; na sexta fase, a solução é interpretada para ver se representa o problema que lhe deu origem, ou seja, avalia-se o modelo. Se nessa avaliação houver dissonâncias com a situação proposta, volta-se à segunda fase e redefine-se o problema, considerando novas variáveis e, eventualmente, altera-se o modelo matemático interpretativo da resolução do problema. Quando terminado todo este ciclo e com a sua validação, o modelo matemático constitui-se um modelo da situação e passa-se à elaboração do respetivo relatório.

O foco da Matemática Aplicada tem sido a solução de problemas da industria e da engenharia. A modelação matemática para além de um método científico associado à matemática 
aplicada é também um método de ensino e aprendizagem (Bassanezi, 2002). A Modelação na educação aplica o mesmo método das Ciências em que a aprendizagem da Matemática, como ciência básica, usa aplicações da vida real. Na educação matemática, as atividades de modelação orientadas para aplicações matemáticas são uma boa forma para aprender conceitos matemáticos (Blum, 2002). Os processos de modelação são uma ferramenta poderosa para o desenvolvimento nos alunos de habilidades de resolução de problemas, trabalho colaborativo e pensamento crítico. O processo de modelação, ciclo da Figura 3, é destinto do processo de ensino tradicional que está centrado no papel do professor.

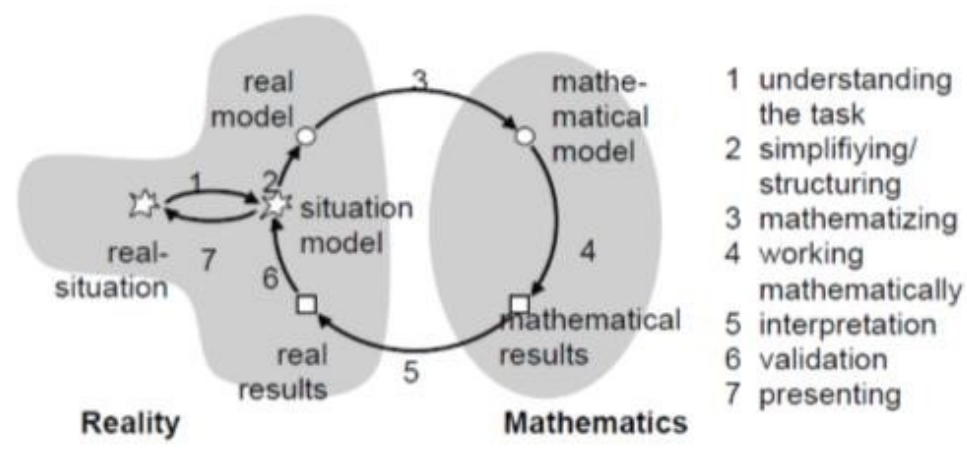

Figura 3: Ciclo de modelação matemática (Cai et al, 2014, p. 17).

Este processo cíclico é consistente com a forma de como muitos dos problemas do mundo real são modelados e promove uma mudança no ensino da matemática tradicional para uma abordagem multidisciplinar. Na educação matemática existem diversos fatores que justificam a inserção modelação matemática nos processos de ensino e aprendizagem (Blomhoj, 2009): a) a modelação matemática reduz as diferenças entre a experiência da vida real dos alunos e a matemática, motiva-os para a aprendizagem da matemática, dá um forte apoio cognitivo para conceptualizações e cria uma cultura de que a matemática é um meio para descrever e compreender as situações da vida real; b) a sociedade tecnológica de hoje exige que se formem alunos especialistas que adquiram competências para criar, analisar e usar criticamente modelos matemáticos. A modelação no ensino é uma estratégia de aprendizagem "onde o mais importante não é chegar imediatamente a um modelo bem sucedido mas, caminhar seguindo etapas onde o conteúdo matemático vai sendo sistematizado e aplicado" (Bassanezi, 2002, p. 38).

\section{METODOLOGIA}

Atendendo à natureza do objetivo deste estudo, avaliar o contributo de tarefas tipo PBL na aprendizagem de conteúdos matemáticos de alunos de cursos de licenciatura em engenharia, tendo como referência as atividades dos alunos em resposta a um trabalho de projeto, as suas dificuldades na resposta às tarefas que the foram propostas e as suas perceções acerca do contributo do trabalho de projeto na sua aprendizagem, a opção metodológica remete para uma abordagem de investigação qualitativa e interpretativa, porque se enfatiza "a descrição, a indução, a teoria fundamentada e o estudo das perceções pessoais" (Bogdan \& Biklen, 1994, p. 11). Para responder aos objetivos do estudo foi implementada uma experiência de ensino, baseada na PBL, com alunos do 1. ano de dois cursos de licenciatura em Engenharia, na unidade curricular de Matemática I. Esta unidade curricular faz parte do plano de estudo do 1. ano dos cursos de 
Engenharia e funciona em semestres letivos diferentes para cada um dos cursos que integraram a experiência. Os 33 alunos de LESEE (Licenciatura em Engenharia de Sistemas Elétricos de Energia) participantes no estudo realizaram, no 1.o semestre, o projeto interdisciplinar "Pêndulo" conjuntamente com três unidades curriculares do 1. ano. Já os 36 alunos de LEM (Licenciatura em Engenharia Mecânica) participantes no estudo realizaram, no 2. semestre, o projeto "Pistão do motor de um automóvel" mas apenas no âmbito da unidade curricular de Matemática I. Em ambos os projetos, as tarefas propostas, para além de serem de índole Matemática, inseriam um contexto de Física/Engenharia, que pressupunham o recurso à modelação matemática e à simulação dos sistemas físicos do pêndulo/ pistão de um motor em software (GeoGebra) e a implementação física de um protótipo. Os projetos foram constituídos por quatro tarefas:

Tarefa 1. Elaboração de um simulador em software do Pêndulo Simples (LESEE) ou um simulador em software do Pistão do motor de um automóvel (LEM);

Tarefa 2. Elaboração de um simulador para as Séries de Funções e com aplicação aos modelos físicos em estudo;

Tarefa 3. Implementação física e programação da sua simulação em GeoGebra; Tarefa 4. Elaboração de relatório e apresentação pública dos seus resultados.

Em face dos requisitos do projeto, os alunos entregaram, em duas fases, respostas escritas preliminares de partes do projeto e posteriormente um relatório final. Estes documentos escritos foram analisados em cada uma dessas fases de entrega e comunicadas aos alunos as suas deficiências no sentido de as corrigir. Posteriormente, os alunos fizeram uma apresentação pública dos resultados do projeto e mostraram os protótipos físicos que executaram. Assim, a informação apresentada neste trabalho deriva da recolha de dados através dos relatórios escritos pelos alunos, das suas apresentações públicas e de uma entrevista. A entrevista teve como finalidade recolher, na última semana de aulas do semestre letivo, as perceções dos alunos acerca do contributo da PBL para a sua aprendizagem.

A informação recolhida é analisada e apresentada segundo as seguintes categorias: (i) Simulação do pêndulo simples (ou do movimento do pistão do motor de um automóvel); (ii) Simulador para séries de funções com a aplicação ao pêndulo (ou do pistão do motor de um automóvel); (iii) Implementação física e simulação de um sistema que faça uso do pêndulo (ou do pistão do motor de um automóvel); (iv) Avaliação do relatório e da apresentação pública dos seus resultados. Para distinguir a sua proveniência, a informação apresentada integra o grupo de trabalho que lhe deu origem segundo a sigla Gi, em que i varia entre 1 e 7 , inclusive.

\section{ANÁLISE DE RESULTADOS}

Neste ponto analisam-se as respostas/atividades dos alunos dos dois cursos às tarefas matemáticas propostas no projeto e as suas opiniões acerca da realização deste tipo de tarefas. 
O projeto "Pêndulo" foi proposto a 7 grupos de 5 alunos do curso de LESEE para a aprendizagem de conceitos matemáticos, físicos e métodos de gestão de projetos através da concretização das suas quatro tarefas.

Simulação do pêndulo simples. A atividade dos alunos na construção de um simulador em GeoGebra com base no modelo de um sistema físico constituído por um pêndulo simples, como o representado na Figura 4, sem forças de atrito a considerar, visou a aprendizagem das funções trigonométricas e sua representação paramétrica. As expressões matemáticas do modelo físico são para pequenas amplitudes $\theta(\mathrm{t})$, um movimento harmónico simples de período $\mathrm{T}$.

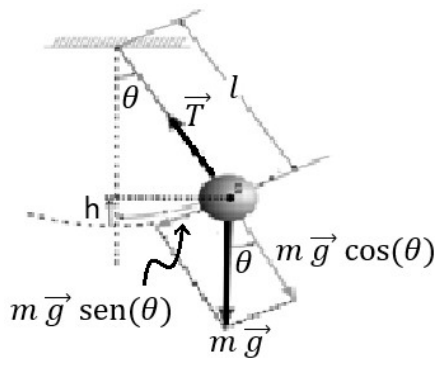

Figura 4: Modelo físico do Pêndulo Simples.

$\mathrm{Na}$ programação do simulador, os alunos colocaram a opção de se poder variar o comprimento do pêndulo $(l)$, o ângulo inicial $\left(\theta_{0}\right)$ do lançamento da massa (valor $\mathrm{m}$ ) e digitar o valor da aceleração da gravidade $(g)$, sendo calculado a frequência angular $(w)$ e frequência $(f)$, como ilustra a interface gráfica da applet construída por um grupo de alunos (G2) na Figura 5.

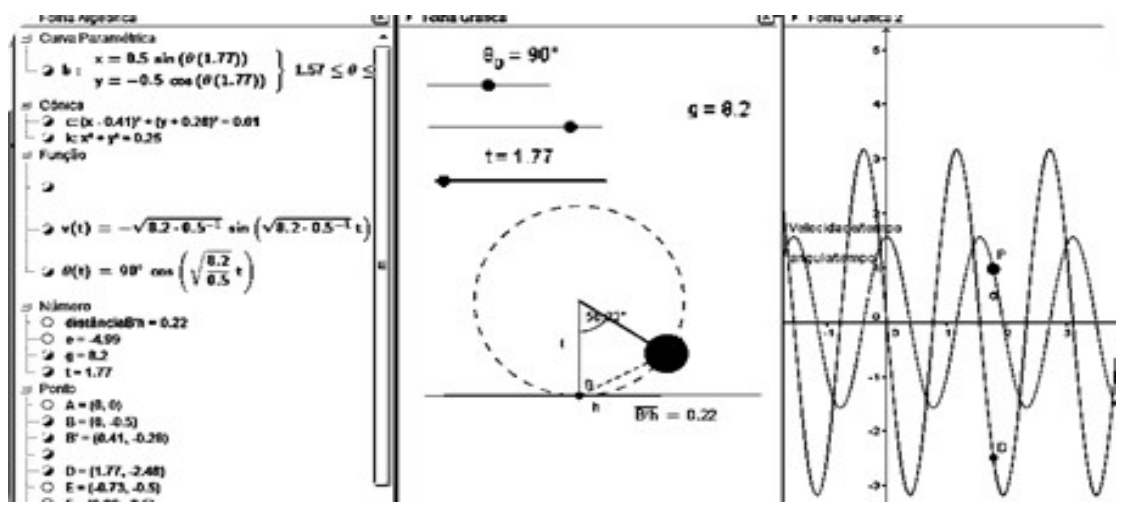

Figura 5: Interface gráfica do simulador de um pêndulo construído por um grupo de alunos (G2).

Da análise das respostas escritas dos alunos (Tabela 2) preliminares à primeira parte das questões colocadas no projeto constatou-se que estes foram capazes de construir o simulador para o modelo do pêndulo.

Tabela 1: Competências definidas no Programa EUR-ACE (Lima, 2012, p. 8).

\begin{tabular}{|l|l|l|l|l|l|l|}
\cline { 2 - 6 } \multicolumn{1}{c|}{} & \multicolumn{5}{c|}{ 1. a Fase de entrega de resultados da Tarefa 1 } \\
\hline Questão & C/PC & E & NR & Observações & Insuficiências mais relevantes & Freq. \\
\hline
\end{tabular}




\begin{tabular}{|c|c|c|c|c|c|c|}
\hline 1.1 & 6 & 1 & 0 & $\begin{array}{l}\text { RA: } 1 \\
\text { RG: } 1\end{array}$ & $\begin{array}{l}\text { Não usar equações paramétricas. } \\
\text { Especificações erradas na applet, I<0. }\end{array}$ & $\begin{array}{l}1 \\
1\end{array}$ \\
\hline 1.2 & 6 & 1 & 0 & RG: 3 & $\begin{array}{l}\text { Ausência de solução analítica de v(t) } \\
\text { Resolução analítica de } v(t)=0 \text { errada. } \\
\text { Não apresenta resolução analítica. }\end{array}$ & $\begin{array}{l}1 \\
1 \\
3\end{array}$ \\
\hline 1.3 & 4 & 1 & 2 & RA: 1 & $\begin{array}{l}\text { Dedução errada do período } \\
(T) \text { errada. }\end{array}$ & 1 \\
\hline 1.4 & 4 & 1 & 2 & $\begin{array}{l}\text { RA: } 1 \\
\text { RG: } 1\end{array}$ & $\begin{array}{l}\text { Cálculo errado do comprimento do fio } \\
\text { do pêndulo do relógio clássico. }\end{array}$ & 1 \\
\hline 1.5 & 5 & 0 & 2 & RA: 5 & & \\
\hline \multicolumn{5}{|c|}{ Classificação/ apreciação global } & Insuf: 0 & \\
\hline
\end{tabular}

PC: Resposta Correta/Parcialmente Correta; E: Resposta Errada; NR: Não Responde; RA: Resposta analítica; RG: Resposta baseada unicamente em cálculos no GeoGebra

$\mathrm{Na}$ análise das respostas dos alunos às questões colocadas no enunciado da tarefa constatou-se que em relação à funcionalidade da programação do simulador só um grupo não considerou a condição do comprimento do fio não poder ser negativo. Para a representação gráfica da velocidade ao longo do tempo de um pêndulo de $50 \mathrm{~cm}$ de comprimento e a determinação da sua velocidade máxima, três grupos apresentaram a explicação com pouco formalismo matemático e um grupo (G2) não entrou em consideração com as equações paramétricas do modelo do sistema físico, como ilustra a imagem da Figura 6.

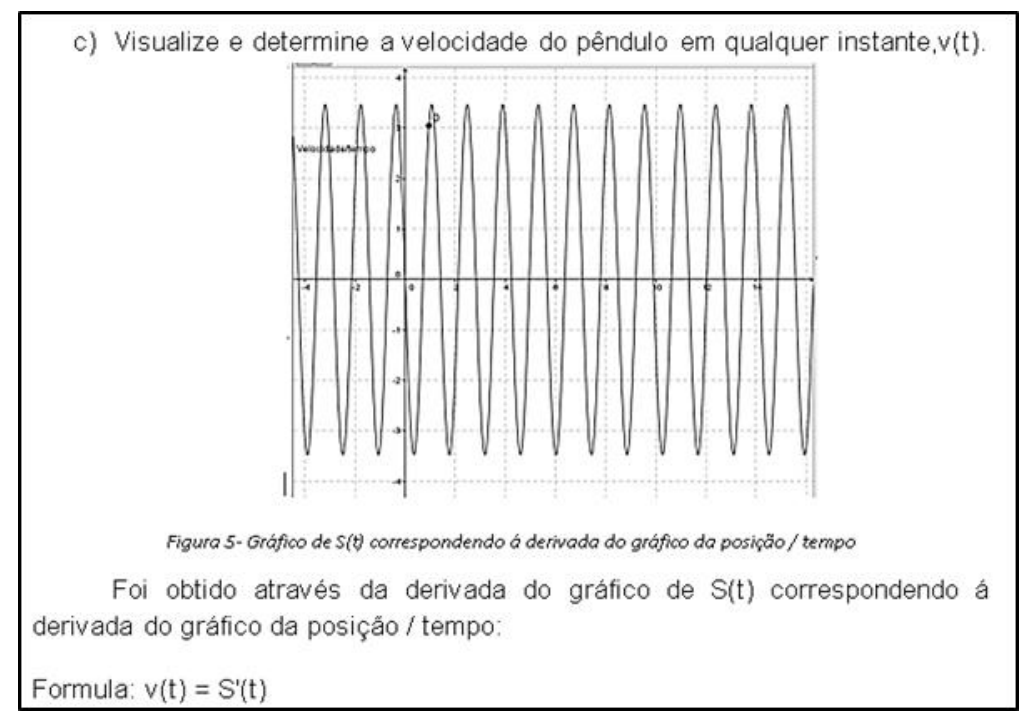

Figura 6: Exemplos de respostas dos alunos à tarefa 1 consideradas insuficientes.

Já dois grupos de alunos não apresentaram qualquer solução para a questão 3,4 e 5 da tarefa.

Relativamente à questão sobre a determinação do valor da aceleração da gravidade, em situações onde a força da gravidade eram diferentes, um grupo deduziu erradamente a expressão matemática do período (T) para o ciclo do movimento do pêndulo $T=2 \pi *$ 
$\sqrt{\frac{g}{l}}(=) g=\left(\frac{T}{2 \pi}\right)^{2} * l$. Um grupo de alunos errou no cálculo do comprimento do pêndulo para a

especificação da construção do relógio de pêndulo.

Simulador para séries de funções com a aplicação ao pêndulo. A resposta à tarefa 2 incidiu sobre a aprendizagem das séries de Taylor num contexto de aplicação ao modelo do pêndulo simples. Pretendia-se que os alunos construíssem um simulador em GeoGebra que permitisse ao utilizador do mesmo encontrar um polinómio de aproximação a uma função. A Figura 7 mostra a interface gráfica da applet construída por um dos grupos de alunos (G5), de acordo com as especificações exigidas na tarefa.

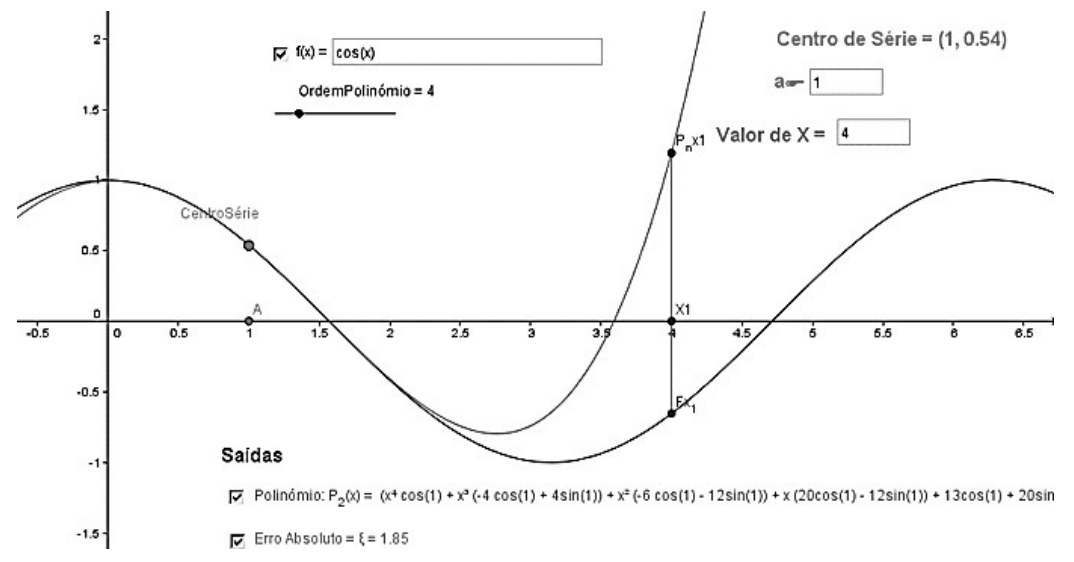

Figura 7: Applet sobre séries de Taylor construída por um grupo de alunos (G5) na tarefa 2.

Essa applet permitia digitar a função $f$, selecionar a ordem do polinómio $(n)$, o centro da série $(a)$ e um ponto de abcissa $x_{1}$ onde analisar a aproximação do polinómio à função real. A elaboração do simulador da série de Taylor pelos alunos auxiliou-lhes nas respostas às questões, tais como: (i) analisar o comportamento da aproximação da função a um polinómio em situações em que os pontos em consideração poderiam pertencer ou não ao intervalo de convergência das séries; (ii) encontrar uma solução com base na série de Taylor e que possa dar resposta a problemas de determinação do valor numérico de uma constante real, tal como $\ln (3)$ ou $\cos ($ /5). Para as situações pedidas no enunciado da tarefa, os alunos confirmaram que os polinómios obtidos pelo simulador eram iguais aos obtidos analiticamente. No entanto, quatro grupos de alunos não determinaram o intervalo de convergência para a aproximação das funções cosseno e logaritmo ao polinómio de Taylor (questão 2.2), como se constata na análise das respostas dos alunos na Tabela 3.

Tabela 3: Resposta dos alunos LESEE à Tarefa 2 na 2. a fase de entrega do projeto ( $\mathrm{N}=7$ Grupos)

\begin{tabular}{|c|c|c|c|l|c|}
\cline { 2 - 6 } \multicolumn{1}{c|}{} & \multicolumn{5}{c|}{ 2. a fase de entrega de resultados da Tarefa 2 } \\
\hline Questão & C/PC & E & NR & Insuficiências mais relevantes. & Freq. \\
\hline 2.1 & 7 & & & & 4 \\
\hline 2.2 & 6 & 1 & & $\begin{array}{l}\text { Não considera o IC na análise de solução. } \\
\text { Não apresenta sugestões para melhorar o erro. }\end{array}$ & 1 \\
\hline
\end{tabular}




\begin{tabular}{|c|c|c|c|l|l|l|}
\hline 2.3 & 2 & 4 & 1 & Applet construída permite obter áreas negativas. & 4 \\
\hline 2.4 & 5 & 1 & 1 & Ausência de significado de centro da série. & 2 \\
\hline 2.5 & 4 & 2 & 1 & Incapacidade crítica sobre os $\Delta t$ apresentados. & 3 \\
\hline $\begin{array}{l}\text { Classificação/ } \\
\text { global }\end{array}$ & Bopreciação & Insuf: $2 \quad$ Suf: $4 \quad$ Bom: \\
\hline
\end{tabular}

Quando foi pedida a determinação do valor de $\ln (3)$, tendo em conta uma aproximação da função $\ln (x)$ a um polinómio de Taylor de ordem $4\left(P_{4}(x)\right)$, os alunos indicaram que o erro da aproximação obtida era elevado, mas não foram capazes de relacionar que este erro era devido ao facto de o ponto de abcissa 3 não pertencer ao intervalo de convergência para o polinómio que tinham determinado.

Uma outra falha encontrada na execução dos softwares que os alunos entregaram para responder à questão 2.3 - determinação da área de regiões definidas pelas funções e pelos polinómios de Taylor definidas na questão - foi que estes não determinavam a área mas apenas o integral definido, como mostra a resolução de um dos grupos (G5) na Figura 8.

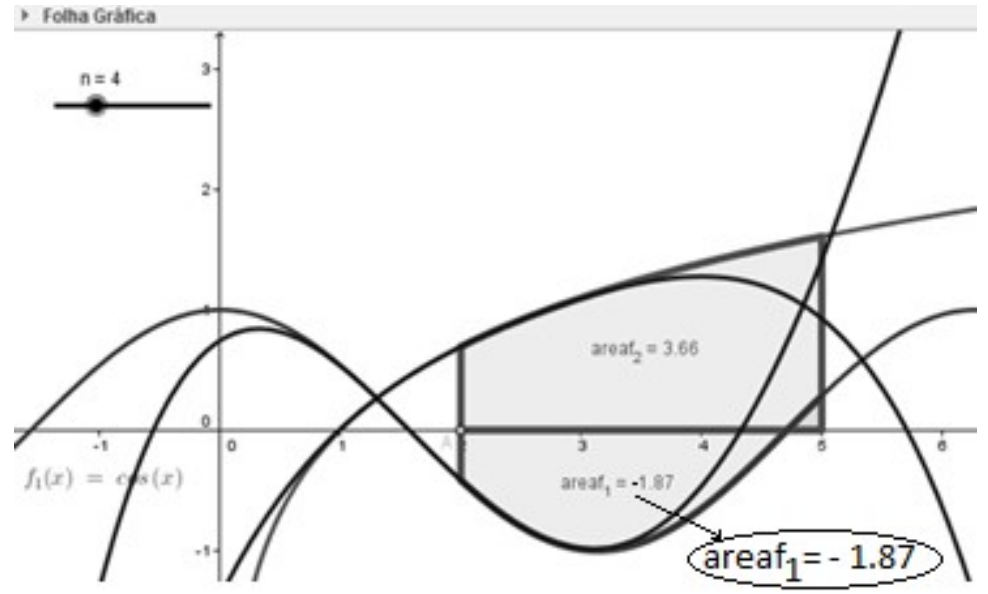

Figura 8: Erro na determinação da área da região sombreada na applet do aluno (G5).

A solução deste problema era simples, os alunos deveriam ter aplicado a expressão integral $\int_{a}^{b}|f(x)| d x$ para determinar as áreas que pretendiam. Também um grupo de alunos não foi capaz de encontrar uma solução adequada para determinar o valor numérico de $\sqrt{e}$ (questão 2.4). 0 grupo selecionou adequadamente a função $e^{x}$ para construir o polinómio de aproximação, mas, no entanto, calculou $P_{n}(\sqrt{ } e)$ e como tal determinou o valor de $e^{\sqrt{\mathrm{e}}}$.

Implementação física e simulação de um sistema que faça uso do pêndulo. A resposta à tarefa 3 visou a construção física de um sistema que incluísse o(s) pêndulo(s) e que exigiu ser simulado no computador, como mostra a solução de um grupo de alunos (G1) na Figura 9. 

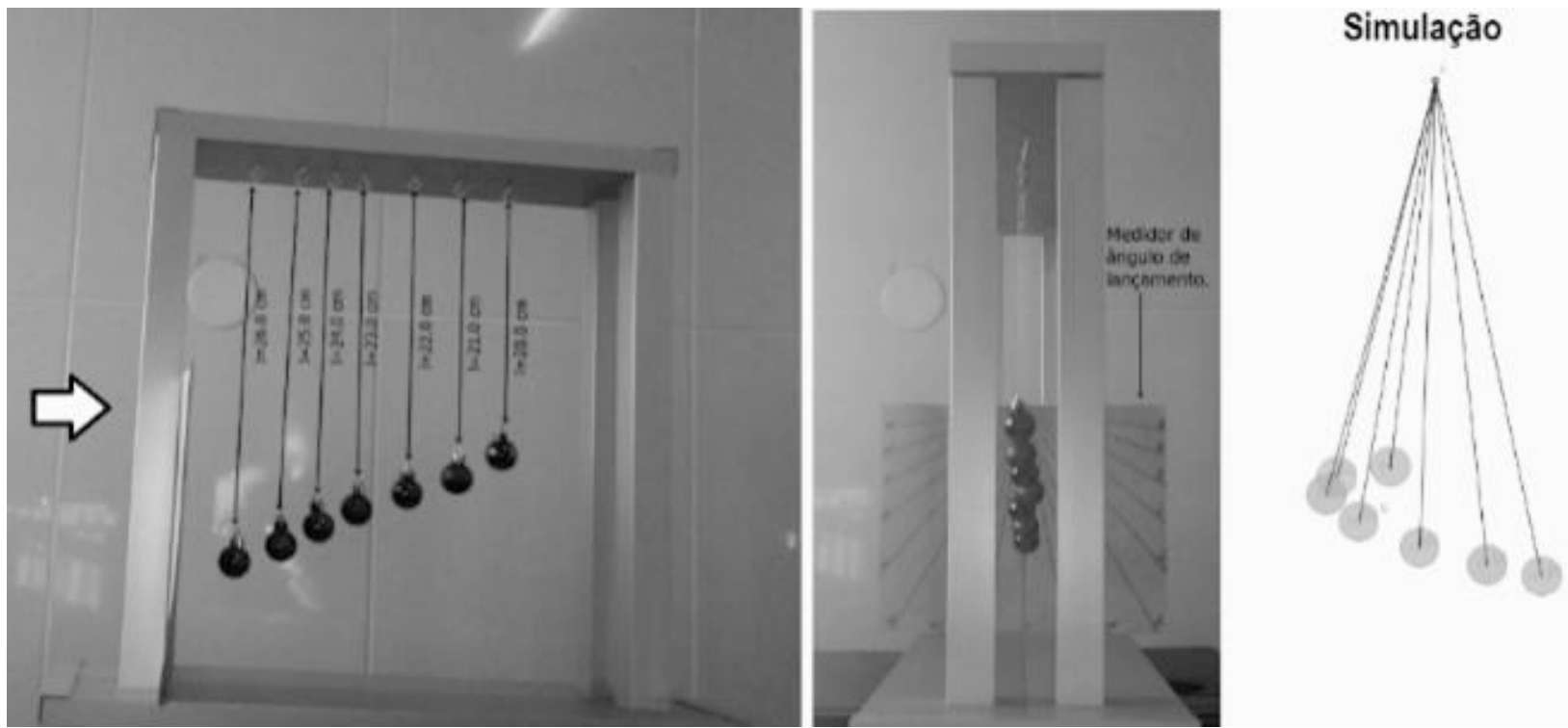

Figura 9: Simulação do sistema físico com múltiplos pêndulos implementado pelos alunos (G1).

A simulação construída no software representa uma visão lateral do movimento das bolas como indica a seta na Figura 9. O objetivo da elaboração da simulação computacional do modelo do protótipo físico construído no projeto interdisciplinar pelos alunos foi o de comparar a situação real com o modelo matemático usado no simulador. Esta fase foi concretizada por todos os grupos com sucesso.

Avaliação do relatório e da apresentação pública dos seus resultados. Na concretização da tarefa 4 pretendia-se que os alunos elaborassem um relatório final do projeto. A análise da escrita desses relatórios pelos alunos está sintetizada na Tabela 4.

Tabela 4: Resultados da elaboração do relatório final pelos alunos do projeto LESEE (N= 7 Grupos)

\begin{tabular}{|c|c|c|c|c|c|}
\hline & \multicolumn{4}{|r|}{ Escrita do relatório final } & \multirow[b]{2}{*}{ Freq } \\
\hline Tarefa & $\mathrm{C} / \mathrm{PC}$ & $\mathrm{E}$ & NR & Insuficiências mais relevantes & \\
\hline 1 & 7 & & 0 & $\begin{array}{l}\text { Não apresenta o problema em análise. } \\
\text { Dedução deficiente das equações diferenciais do } \\
\text { movimento pêndulo. } \\
\text { Justificações matemáticas analíticas insuficientes. } \\
\text { Apresenta resultados numéricos sem análise gráfica. } \\
\text { Resolução analítica com ausência de análise gráfica. }\end{array}$ & $\begin{array}{l}2 \\
2 \\
1 \\
1 \\
1\end{array}$ \\
\hline 2 & 7 & & 0 & $\begin{array}{l}\text { Não considera IC na solução do problema. } \\
\text { Não comentar as soluções obtidas para } P_{2}(x), P_{3}(x) \text { e } \\
P_{10}(x) \text {. } \\
\text { Não corrigir todas as deficiências detetadas nos pré- } \\
\text { relatórios. }\end{array}$ & $\begin{array}{l}4 \\
2 \\
2\end{array}$ \\
\hline \multicolumn{4}{|c|}{$\begin{array}{l}\text { Formatação do } \\
\text { documento }\end{array}$} & $\begin{array}{l}\text { Não cumpriu. } \\
\text { Cumpriu. }\end{array}$ & $\begin{array}{l}2 \\
5\end{array}$ \\
\hline \multicolumn{4}{|c|}{$\begin{array}{l}\text { Classificação/apreciação } \\
\text { global }\end{array}$} & Insuf: $0 \quad$ Suf: 2 & \\
\hline
\end{tabular}


A maior parte dos relatórios tinha um formato e uma escrita adequada, no entanto no conteúdo de alguns relatórios os alunos não corrigiram algumas deficiências detetadas na primeira fase da entrega do pré-relatório, particularmente a análise do intervalo de convergências das séries de funções, como se contata na tabela 4 . A resposta à tarefa 4 visou, ainda, uma apresentação pública dos resultados do projeto, como mostram as imagens da Figura 10 de algumas dessas apresentações dos alunos.
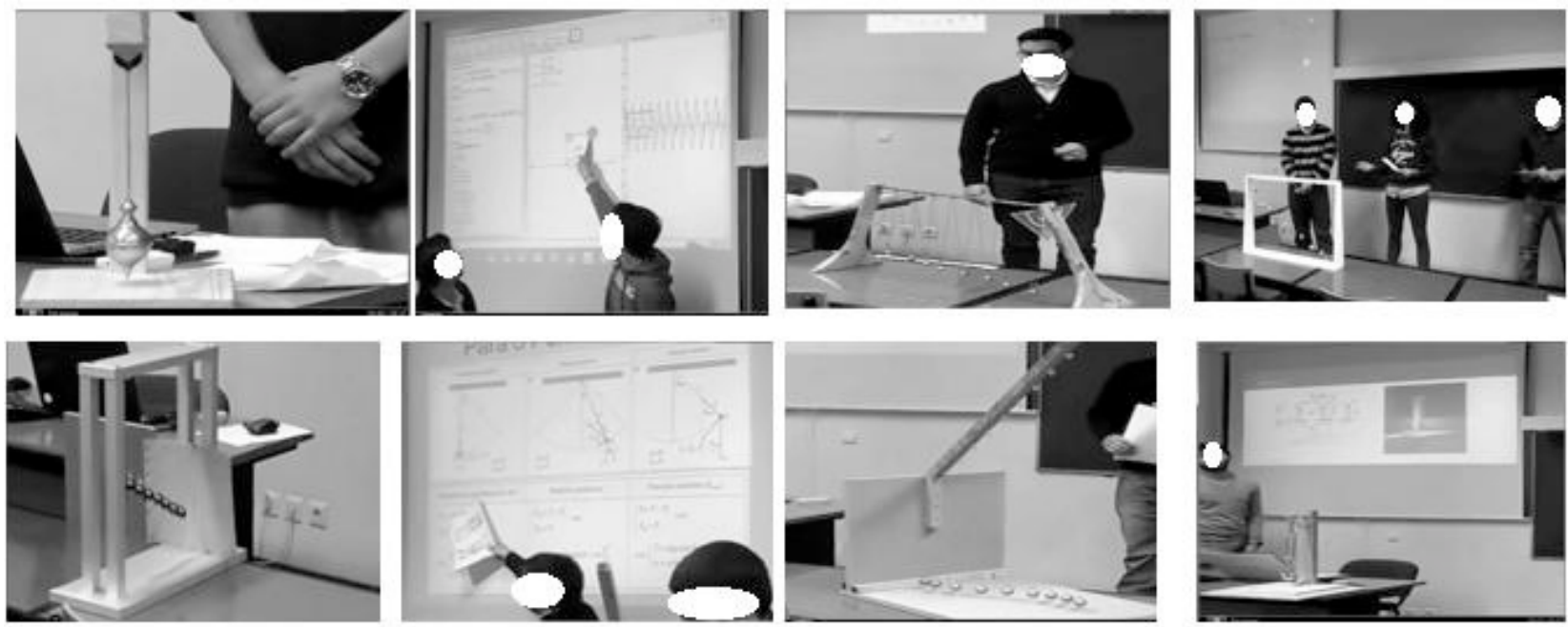

Figura 10: Apresentação pública dos alunos de LESEE dos resultados da tarefa de Projeto.

$\mathrm{Na}$ apresentação pública dos resultados do projeto Pêndulo, os alunos fizeram uso das atuais ferramentas para a projeção de diapositivos e a visualização dos resultados gráficos das applets de simulação que tinham desenvolvido. Estes fizeram, ainda, demonstrações com os protótipos físicos que tinham construído para responder às questões colocadas no enunciado do projeto, como se constata nos resultados sintetizados na Tabela 5.

Tabela 5: Apresentação pública dos alunos de LESEE dos resultados do projeto ( $N=7$ Grupos)

\begin{tabular}{|c|c|c|c|c|}
\hline \multicolumn{5}{|c|}{ Apresentação pública de resultados do projeto } \\
\hline PowerPoint & Prezzi & GeoGebra & Apresentação do protótipo. \\
\hline 6 & 1 & 7 & 7 \\
\hline Classificação/ apreciação global & Insuf: 0 & Suf: 2 & Bom: 5 \\
\hline
\end{tabular}

Os alunos mostraram a comparação de resultados obtidos com a simulação em software e do sistema real do pêndulo. Nas conclusões, os alunos comentaram aspetos relativos à integração do projeto nas diversas unidades curriculares. Neste sentido, um grupo (G3) na apresentação das conclusões do trabalho que realizou refere que:

O professor falou na articulação do trabalho entre as três unidades curriculares e comentou que a Física não ia entrar, mas realmente a Física esteve sempre presente. Sem a Física, provavelmente não teríamos conseguido responder a todas as perguntas da tarefa de Projeto. Pensamos que houve uma forte articulação entre os conteúdos programáticos, estavam interligados e este tipo de formação é uma mais-valia para o nosso curso. Desta forma, aprendemos em diferentes contextos e isso ajuda-nos a assimilar os conceitos. A unidade curricular de MTENG foi importante para nos ajudar a construir os relatórios, a fazer apresentações em público, na gestão de tempo e dos 
recursos. O trabalho de preparação do projeto, a interligação das unidades curriculares e o trabalho de grupo deu-nos outras competências úteis para o futuro no mercado de trabalho.

Nos comentários dos alunos deste grupo é perceptível que esta tarefa lhes proporcionou motivação para a aprendizagem e reconhecem que adquiriram novas competências com a realização do projeto. Na maioria dos grupos, os alunos fizeram este tipo de comentários nas suas apresentações.

Outro grupo (G4), na apresentação dos seus resultados, justificou as diferenças que existiram no movimento sistema real do pêndulo construído e a simulação com o seu modelo físico e matemático.

Não conseguimos ter um movimento do sistema real igual ao da simulação devido à resistência do ar e porque as massas, embora não entrem, em termos teóricos, nas expressões do modelo matemático-físico, na realidade introduzem alterações. Ao fim de algum tempo, as bolas deixam de se movimentar devido à resistência do ar.

Os alunos de outro grupo (G5) reconhecem a aquisição de novas competências na aprendizagem com a tarefa.

Com este trabalho conseguimos melhorar as nossas capacidades de gestão e estruturar projetos com aquilo que aprendemos em MTENG, ganhamos uma nova perspetiva sobre a manipulação de fórmulas com o GeoGebra e tivemos uma melhor compreensão da aplicação da matemática a uma situação real, o pêndulo.

Os outros grupos, na apresentação das suas conclusões, indicaram contributos com a realização do projeto semelhantes aos apresentados nas transcrições anteriores. Estas conclusões dos alunos mostram o interesse e a motivação que cria a realização das tarefas do tipo PBL nos alunos.

\subsection{Realização da tarefa de projeto pelos alunos de LEM}

Seguidamente apresenta-se uma análise das respostas dos 6 grupos, constituídos por 5 alunos, do curso de LEM às tarefas que constavam no projeto "Pistão do motor de um automóvel.

Simulação do movimento do pistão do motor de um automóvel. As respostas à tarefa 1 dos alunos visaram a aprendizagem das funções paramétricas e trigonométricas aplicadas ao modelo físico do pistão do motor de um automóvel. Pretendia-se que os alunos tomassem contacto e introduzissem as alterações que achassem necessárias ao simulador, pré-construído em GeoGebra, do sistema físico do movimento do pistão de um automóvel, como o representado na Figura 11. 


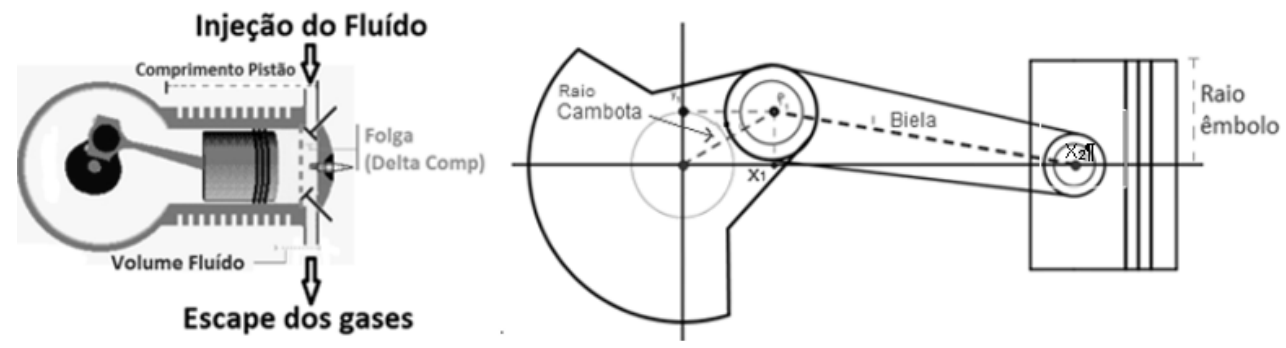

Figura 11: Modelo físico do Pistão de um automóvel.

As expressões matemáticas para o modelo físico do movimento do pistão de um automóvel, que os alunos deveriam deduzir na escrita do relatório do projeto, são:

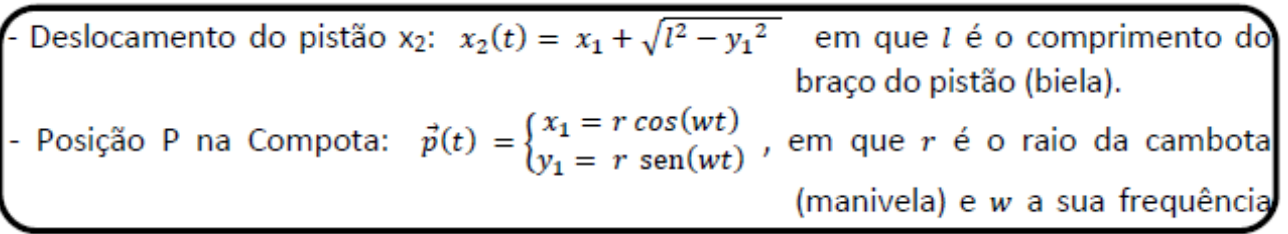

O simulador deveria permitir que o utilizador pudesse variar o comprimento do braço do pistão (biela), o raio da cambota (manivela), a frequência angular da cambota, raio do êmbolo e o comprimento do êmbolo. Com o simulador, todo o movimento do sistema do pistão podia ser animado para analisar o comportamento dos seus elementos físicos. O simulador permitiu apoiar os alunos nas suas respostas a um conjunto de questões de índole matemática no contexto físico deste sistema, tais como: Determinação e visualização do movimento do êmbolo do pistão; determinação das dimensões dos elementos do pistão.

Na primeira fase da entrega da tarefa 1 verificou-se que dois grupos de alunos (G4 e G5) não apresentaram, no prazo estabelecido o pré-relatório das suas atividades, como se constata da análise da Tabela 6 relativa à síntese das respostas dos grupos à tarefa.

Tabela 6: Resposta dos alunos de LEM à Tarefa 1 na 1. a fase de entrega do projeto $(\mathrm{N}=6)$

\begin{tabular}{|c|c|c|c|c|c|c|}
\hline Tarefa1 & \multicolumn{6}{|c|}{ Respostas à 1.a fase de entrega de resultados do projeto LEM } \\
\hline $\begin{array}{l}\text { Questã } \\
\text { ○ }\end{array}$ & $\mathrm{C} / \mathrm{PC}$ & $\mathbf{E}$ & NR & Obser. & Insuficiências mais relevantes & F. \\
\hline 1 & 4 & 0 & 2 & $\begin{array}{l}\text { RA: } 1 \\
\text { RG: } 1\end{array}$ & $\begin{array}{l}\text { Ausência de justificações matemáticas } \\
\text { analíticas dos resultados obtidos. } \\
\text { Ausência de representações gráficas de } \\
\text { resultados } \\
\text { Sem formato de relatório. }\end{array}$ & $\begin{array}{l}4 \\
- \\
1 \\
2\end{array}$ \\
\hline 2 & 2 & 0 & 4 & RG: 3 & Ausência de solução analítica dos resultados. & 2 \\
\hline Classific & o/ ap & & 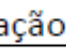 & obal & Insuf: 1 & \\
\hline
\end{tabular}

Nesta primeira fase de apresentação de resultados pelos alunos constatou-se que a maioria dos grupos apresentou respostas às questões com pouco formalismo matemático e essencialmente baseadas em resultados diretos obtidos através do software GeoGebra. Genericamente, a apreciação global desta atividade escrita dos alunos considerou-se não satisfatória.

Simulador para Séries de Funções com aplicação ao pistão do motor de um automóvel. A tarefa 2 visou a aprendizagem das séries de Taylor num contexto de aplicação ao modelo físico do 
pistão do motor de um automóvel. Nesta tarefa foi pedido aos alunos que elaborassem em GeoGebra um simulador para representar séries de Taylor/MacLaurin de uma função cujos objetivos eram os mesmos da tarefa 2 apresentada aos alunos de LESEE. A Figura 12 mostra a interface gráfica de uma dessas applets produzida por um dos grupos (G3).

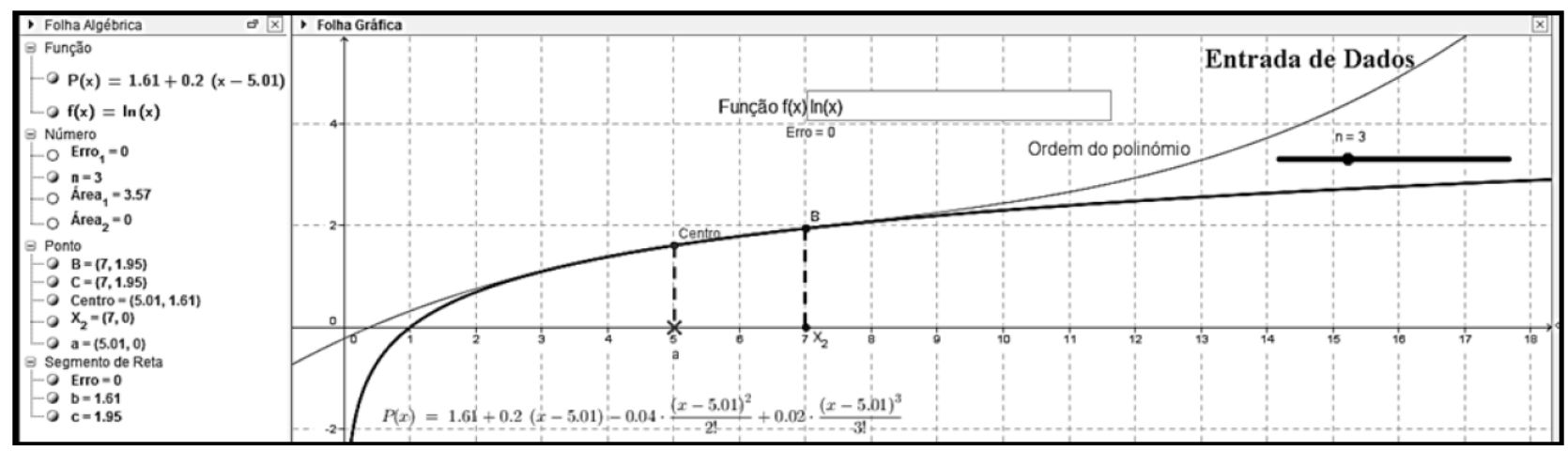

Figura 12: Applet sobre séries de Taylor construída por um grupo (G3) para a tarefa 2 do projeto do pistão.

$\mathrm{Na}$ entrega do pré-relatório com os resultados da $2^{\mathrm{a}}$ tarefa de projeto, apenas um grupo de alunos o fez dentro do prazo estabelecido. Este grupo teve dificuldades em distinguir centro da série de Taylor da abcissa do ponto da função na aproximação a um polinómio de Taylor. Daí que a atividade de resposta do grupo não foi capaz de fazer uma boa opção de escolha para determinar $\sqrt{e}$ por aproximação a um polinómio de Taylor. Este grupo escolhe $X=e^{\sqrt{e}}$ e $f(x)=\ln (x)$ em resposta à questão e com essa opção não era propriamente fácil analisar o erro da respetiva aproximação sem recurso unicamente a tecnologias de cálculo. Nesta fase, estes alunos obtiveram uma classificação de suficiente para a sua atividade de resposta à tarefa.

Implementação física e simulação de um sistema que faça uso do pistão de um automóvel. $\mathrm{Na}$ tarefa 3 pretendia-se que os alunos contruíssem um protótipo físico e um simulador 3D em software GeoGebra representativo da dinâmica do movimento de um pistão do motor de um automóvel. Apenas quatro grupos realizaram o protótipo físico e dois grupos (G1 e G2) apresentaram o simulador 3D, como se apresenta na Figura 13.
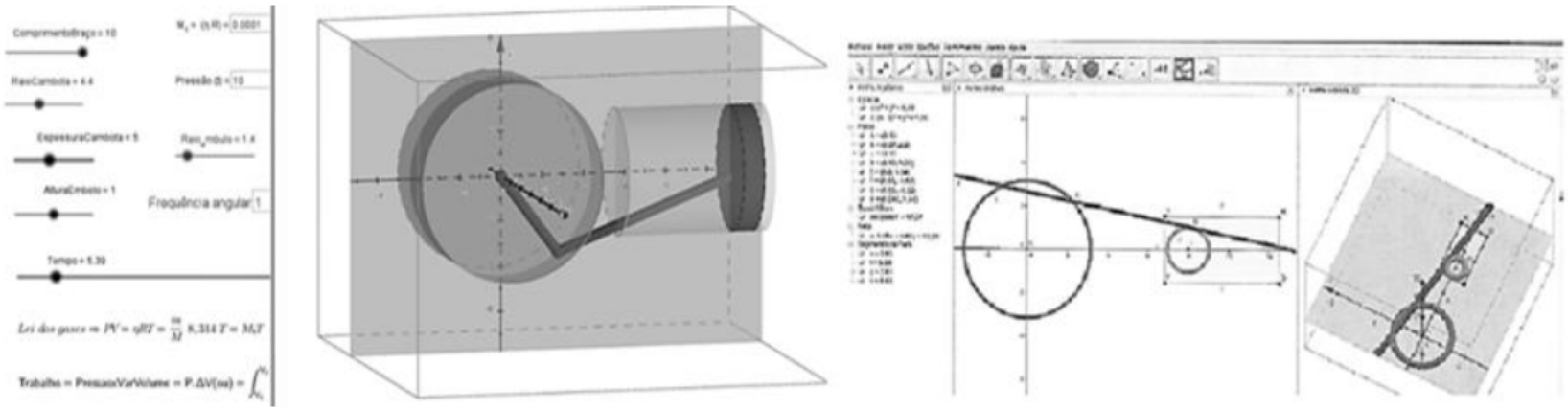

Figura 13: Simuladores 3D do pistão de um automóvel realizado por dois grupos de alunos.

Pode-se considerar o segundo simulador da Figura 13 rudimentar, tendo em conta que estes alunos são de engenharia mecânica e, por isso, Ihes é exigido um pouco mais em termos de 
desenho de sistemas mecânicos. Os outros grupos referem que não foram capazes de concretizar o simulador 3D porque, segundo eles, tinham poucos conhecimentos do GeoGebra.

Avaliação do relatório e da apresentação pública dos seus resultados. Na resposta à tarefa 4 pretendia-se que os alunos elaborassem um relatório final do projeto. Metade desses relatórios apresentou um formato de escrita considerado insuficiente, sem introdução matemática às temáticas, sem índice e conclusões adequadas, como se constata da análise da Tabela 7.

Tabela 7: Resultados da elaboração do relatório final pelos alunos do projeto LEM ( $N=6$ )

\begin{tabular}{|c|c|c|c|c|c|}
\hline & \multicolumn{5}{|c|}{ Elaboração do relatório final } \\
\hline Tarefa & $\mathrm{C} / \mathrm{PC}$ & $\mathbf{E}$ & NR & Insuficiências mais relevantes & Freq. \\
\hline 1 & 6 & & 0 & $\begin{array}{l}\text { Não apresenta o problema em análise } \\
\text { Justificações matemáticas analíticas insuficientes } \\
\text { Resolução maioritariamente analítica das questões }\end{array}$ & $\begin{array}{l}1 \\
2 \\
1\end{array}$ \\
\hline 2 & 5 & & 1 & $\begin{array}{l}\text { Não considera IC na solução do problema } \\
\text { Justificações matemáticas analíticas insuficientes } \\
\text { Não constrói o simulador para a série de Taylor }\end{array}$ & $\begin{array}{l}1 \\
2 \\
1\end{array}$ \\
\hline 3 & 2 & & 4 & $\begin{array}{l}\text { Não foi capaz de construir applet 3D de simulação } \\
\text { do movimento de um pistão }\end{array}$ & 4 \\
\hline \multicolumn{4}{|c|}{ Formatação do texto } & $\begin{array}{l}\text { Não cumpriu } \\
\text { Cumpriu }\end{array}$ & $\begin{array}{l}3 \\
3 \\
\end{array}$ \\
\hline Classifica & o/apr & Iaça & obal & Insuf: 0 & \\
\hline
\end{tabular}

$\mathrm{Na}$ análise dos relatórios finais observou-se que dois grupos de alunos apresentaram os resultados às questões da tarefa 1 baseados quase só nos gráficos do GeoGebra, com pouco formalismo nas justificações. Já um grupo de alunos (G7) responde apenas de forma analítica a todas as questões e sem apresentar os gráficos (Figura 14).

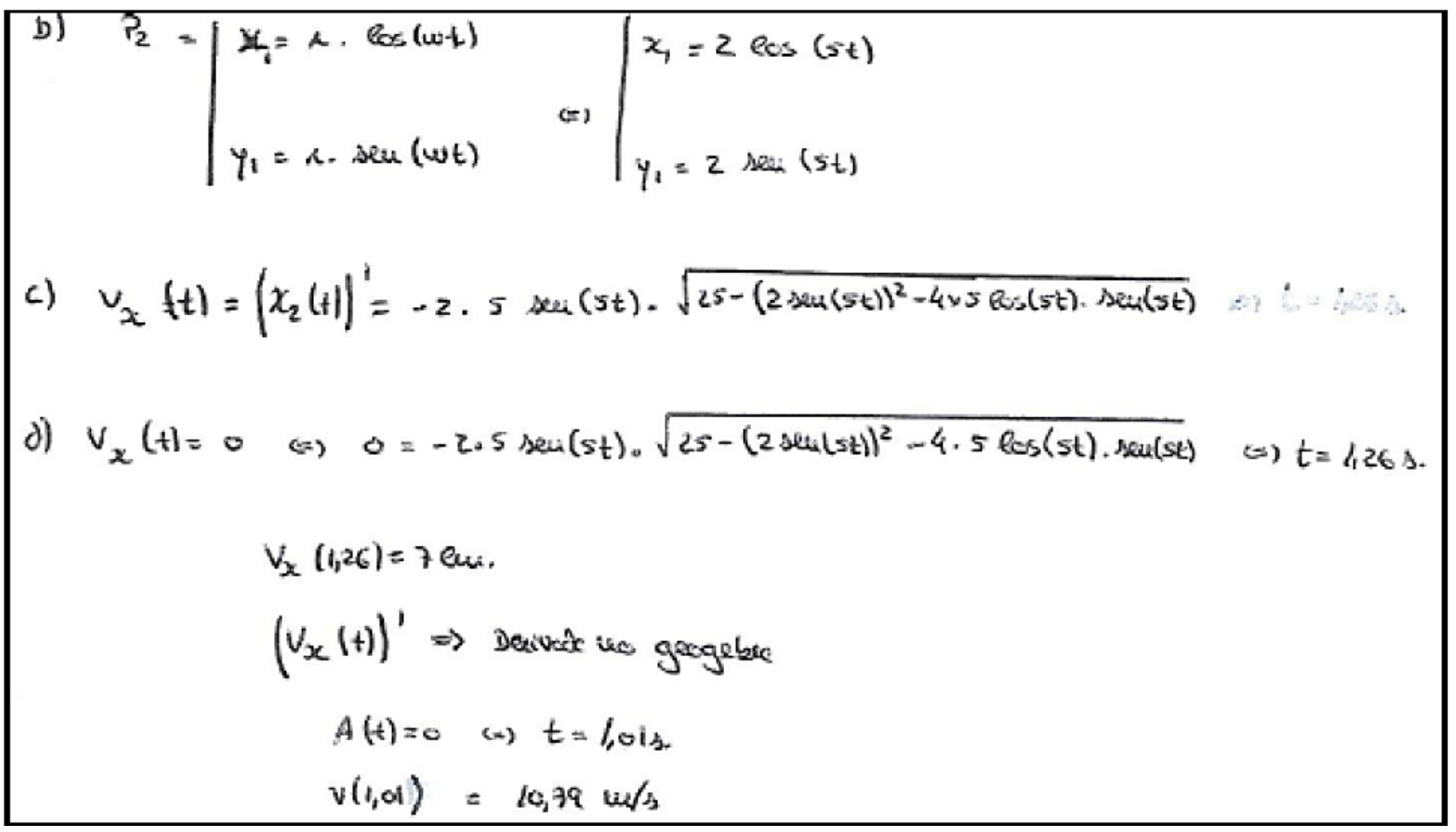


Figura 14: Ausência de resposta gráfica de um grupo de alunos (G7) às questões da tarefa 1 do projeto.

Os restantes três grupos de alunos levaram em conta as sugestões dos professores para a correção dos erros cometidos na primeira fase da entrega do pré-relatório e apresentam respostas adequadas às questões solicitadas na tarefa 1 do projeto no seu relatório final.

$\mathrm{Na}$ análise das respostas escritas no relatório final dos alunos constata-se (Tabela 6) que apenas um grupo de alunos (G7) não respondeu à tarefa 2 e todos os outros foram capazes de contruir a applet de simulação e análise da série de Taylor/MacLaurin de uma função. Na análise da aproximação do polinómio de Taylor de 4. ${ }^{a}$ ordem à função $\cos (x)$ no ponto de abissa $\mathrm{x}=\frac{3}{2}$, dois grupos de alunos (G1 e G2) afirmam erradamente que o erro era nulo, porque não aumentaram as casas decimais na saída de resultados no software, como ilustra uma das resoluções na Figura 15.

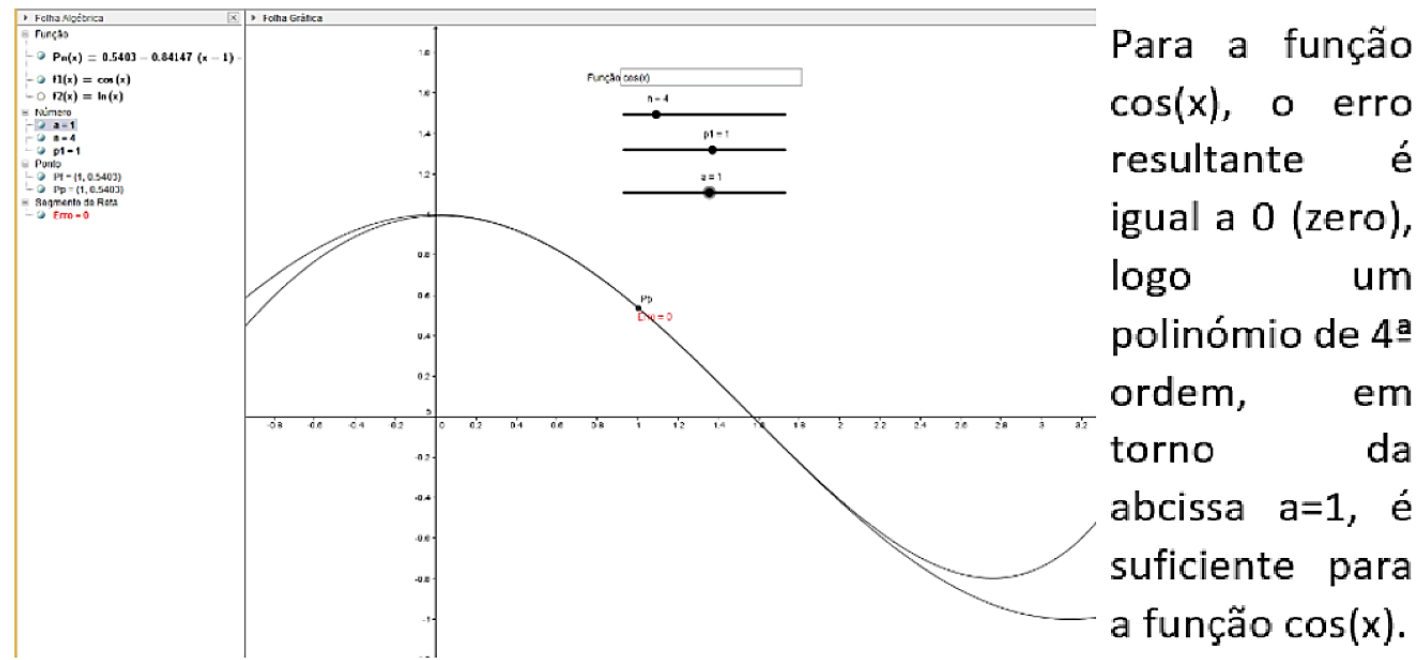

Figura 15: Resolução de um grupo de alunos (G2) para a determinação cos (3/2) através de $P_{4}(x)$.

Um grupo de alunos (G1) não determinou o intervalo de convergência da aproximação da série de Taylor à função logarítmica, não sendo capaz de justificar adequadamente o facto de o erro ser elevado na aproximação do polinómio de ordem $4\left(P_{4}(x)\right)$ ao valor de $\ln (3)$, no ponto de abcissa 3.

A tarefa 2 do projeto tinha ainda como objetivo a aplicação das séries de Taylor na resolução de um problema da termodinâmica no contexto do pistão do motor de um automóvel. No sentido de apoiar as respostas dos alunos, foi acrescentado à primeira applet algumas funcionalidades neste âmbito, como ilustra a Figura 16. 


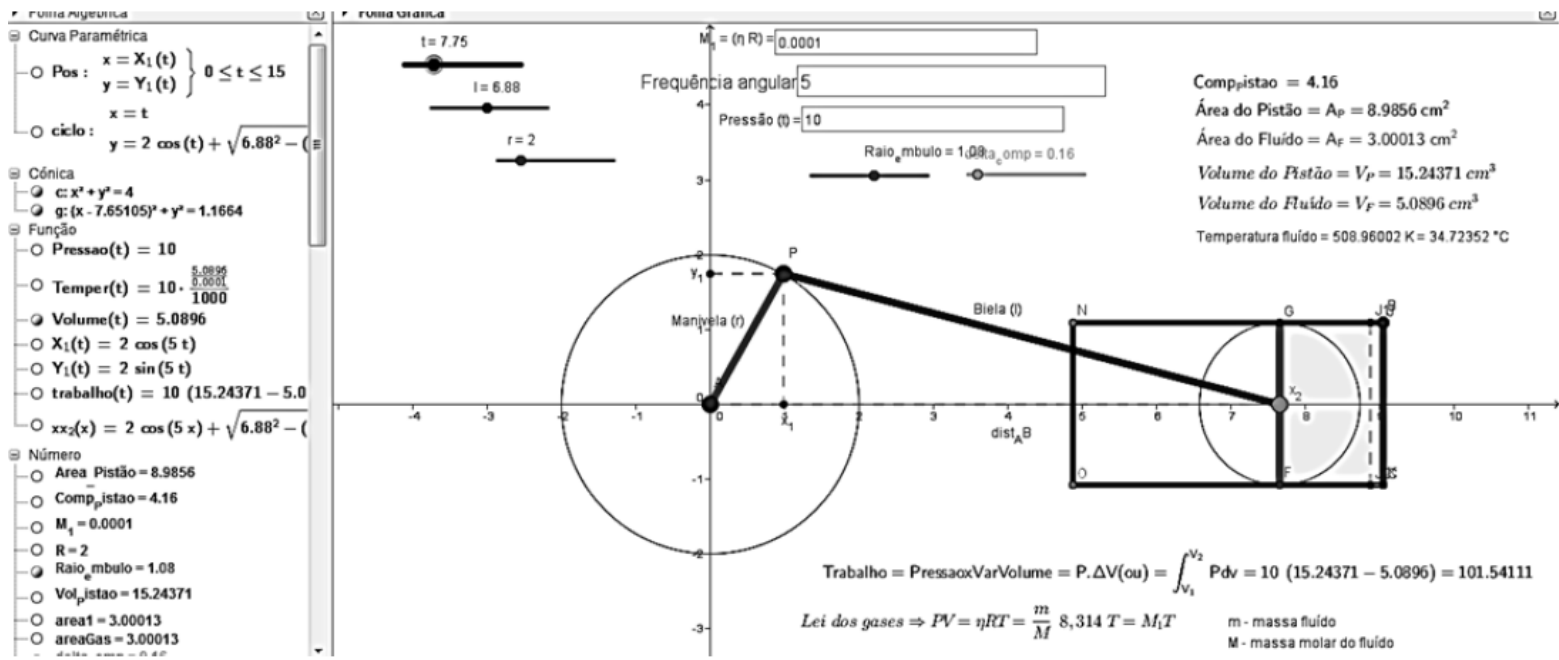

Figura 16: Applet de simulação da dinâmica e do comportamento térmico do pistão de um automóvel.

Este simulador, para além de admitir os mesmos dados do primeiro simulador, permitia a introdução do comprimento $d x$ da folga delta (ponto morto superior) e de alguns dados relacionados com a termodinâmica do sistema mecânico necessários à tarefa 2, tais como:

- A constante $\mathrm{M}_{1}$, que relaciona a massa do fluído injetado $(m)$ com a sua massa molar (M) pela expressão $\frac{m}{M} 8,314=M_{1}$;

- A expressão da pressão $P(v)$ a que o fluido estaria sujeito no interior do êmbolo.

Com o simulador, os alunos puderam visualizar e determinar a dinâmica da variação do volume e a temperatura do fluído no interior do êmbolo resultante do movimento do pistão.

Para o ciclo de Otto, a determinação do trabalho do pistão em função do volume do fluído no seu interior ( $w(v)$ ) causou muitas dificuldades aos alunos e dois grupos não apresentaram qualquer resolução. Dois outros grupos de alunos apresentaram respostas pouco comentadas, baseadas nos resultados obtidos com o simulador e analiticamente, como ilustra a resolução na Figura 17.

Podemos realizar por dois processos.

12 - Sendo $\mathrm{P}(\mathrm{v})=4+3 \ln \left(\left(2+\cos \left(\frac{\mathrm{v}-\mathrm{dx}}{\mathrm{s}}-\pi\right)\right)^{-1}\right)$, e umavez que $\mathrm{W}(\mathrm{v})=\int_{v_{1}}^{v_{2}} \mathrm{P}$ dv, para sabemos $\mathrm{W}(\mathrm{v})$ te mos de fazer o inte gral de finido dafunçăo $P(v)$ que varia de $v_{1} a v_{2}$.

2. - Podemosfazer $W(v)=P d v$.

12 Processo:

$$
\begin{aligned}
& W(v)=\int_{v_{1}}^{v_{2}} P d v \Leftrightarrow W(v)=\int_{v_{1}}^{v_{2}} 4+3 \ln \left(\left(2+\cos \left(\frac{v-d x}{3}-\pi\right)\right)^{-1}\right) \Leftrightarrow \\
& \Leftrightarrow W(v)=\int_{v_{1}}^{v_{2}} 4+\int_{v_{1}}^{v_{2}} 3 \ln \left(\left(2+\cos \left(\frac{v-d x}{3}-\pi\right)\right)^{-1}\right) \Leftrightarrow \\
& \Leftrightarrow W(v)=4 x+3\left(2+\cos \left(\frac{\left(v_{2}-v_{1}\right)-d x}{3}-\pi\right)\right)^{-1}\left[\ln \left(\left(2+\cos \left(\frac{\left(v_{2}-v_{1}\right)-d x}{3}-\pi\right)\right)^{-1}\right)+\left(2+\cos \left(\frac{\left(v_{2}-v_{1}\right)-d x}{3}-\pi\right)\right)^{-1}\right]
\end{aligned}
$$

2ㅇ Processo:

$W(v)=P d v \Leftrightarrow W(v)=P\left(v_{2}-v_{1}\right) \Leftrightarrow W(v)=P\left(v_{2}-v_{1}\right)$, onde $P$ é um valor de entrada no Geogebra. 
Figura 17: Resolução da questão 2.5. de um grupo de alunos na tarefa 2 do projeto.

Nesta resolução, os alunos não fazem uma discussão em torno do significado do volume $v_{1}$ e $v_{2}$, nem apresentam um gráfico da variação do trabalho em função de v. Já um outro grupo de alunos apresenta uma solução errada, afirmando que w (v) seria o integral definido limitado pelos ciclos de Otto na expansão e na compressão. Na realidade, para o problema interessava apenas considerar o integral representativo da área da região limitada pela curva da pressão do ciclo de Otto na compressão e o eixo do volume, definido entre o volume mínimo e máximo do pistão.

Das tarefas do projeto do curso de LEM fazia parte uma atividade de apresentação pública de resultados obtidos pelos grupos em resposta às tarefas que lhe foram propostas a realizar, como mostram algumas imagens na Figura 18 dessas apresentações realizadas pelos alunos.
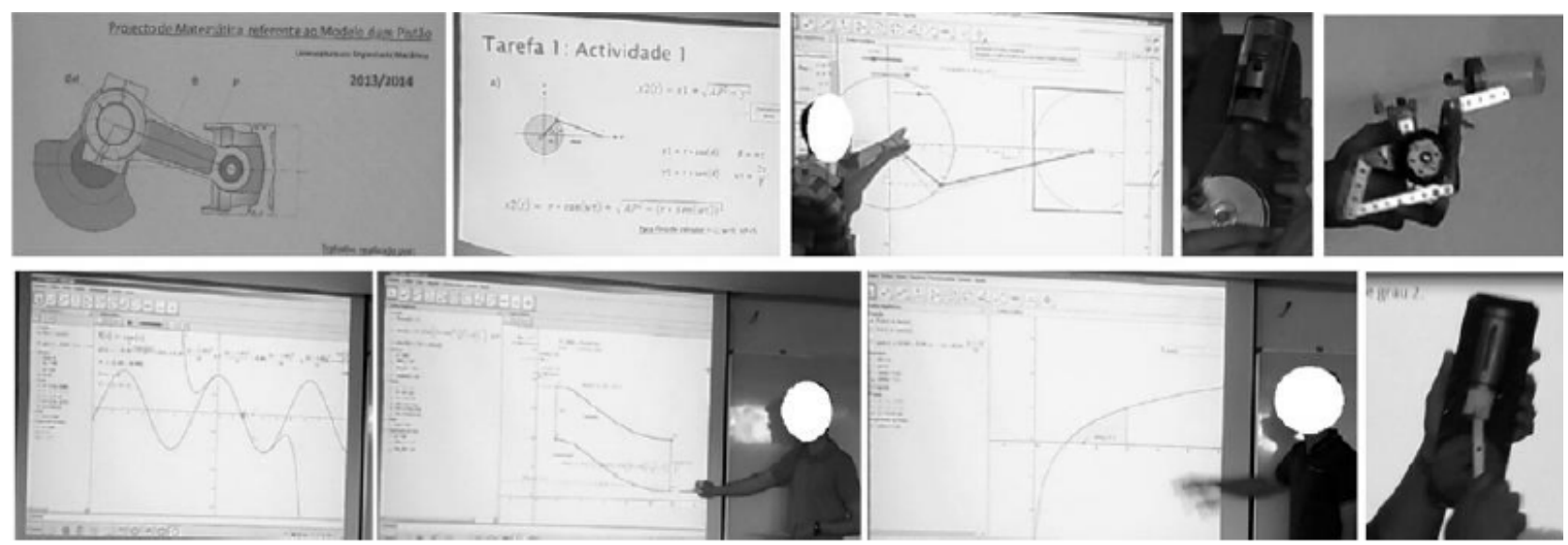

Figura 18: Apresentação pública dos alunos LEM dos resultados do projeto Pistão de um automóvel.

Em resposta à tarefa de apresentação pública de resultados do projeto, apenas um grupo (G6) não realizou essa atividade (Tabela 8) alegando não ter tido tempo para fazer a preparação da sua apresentação.

Tabela 8: Apresentação pública dos alunos de LEM dos resultados do projeto ( $N=6)$.

\begin{tabular}{|c|c|c|c|c|c|}
\hline \multicolumn{5}{|c|}{ Apresentação pública } \\
\hline NR & PowerPoint & Doc. relatório & GeoGebra & $\begin{array}{l}\text { Em } \\
\text { Vídeo }\end{array}$ & Apresentação do protótipo. \\
\hline 1 & 4 & 1 & 5 & 1 & 4 \\
\hline \multicolumn{2}{|l|}{ Classificação/ apreciação global } & Insuf: 1 & Suf: $1 \quad$ Bom: 3 \\
\hline
\end{tabular}

Na apresentação pública de resultados do projeto Pistão de um automóvel, os alunos maioritariamente expuseram os seus resultados com apoio em PowerPoint, apresentaram diversas simulações gráficas através das applets que desenvolveram em GeoGebra e fizeram demonstrações com os protótipos físicos que construíram para responder às questões das tarefas do projeto. No entanto, um grupo fez a sua apresentação baseada no documento do próprio relatório com transições explicativas ao GeoGebra. Na maioria das apresentações, os alunos justificaram alguns dos resultados que não tinham justificado na escrita do relatório final do projeto. Esta fase das apresentações permitiu que alguns grupos complementassem ou melhorassem algumas das atividades em relação ao que tinham escrito nos seus relatórios. Por 
exemplo, um grupo de alunos (G1) que entregou um relatório totalmente escrito à mão e sem qualquer gráfico, melhora essas componentes nas suas projeções como se ilustra na Figura 19.

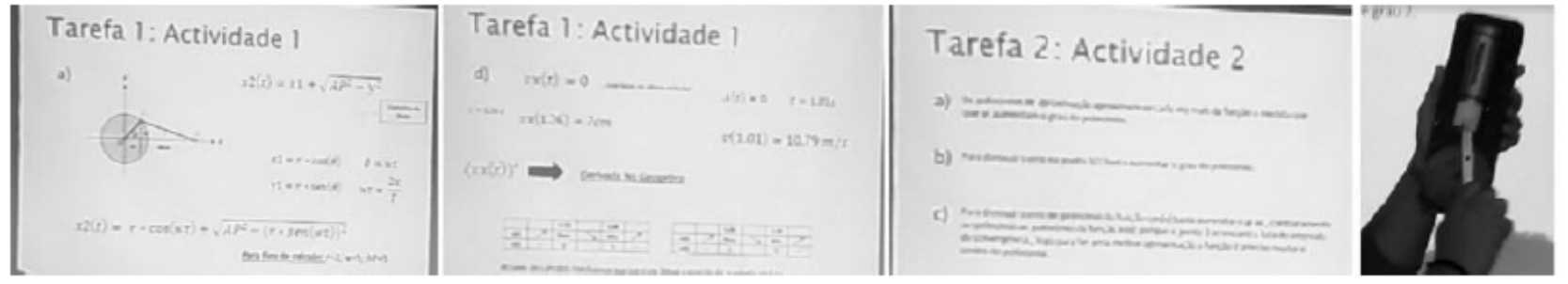

Figura 19: Apresentação de um grupo de alunos (G1) da tarefa de projeto do Pistão do automóvel.

Um outro grupo (G2), na sua apresentação, consegue justificar as suas respostas às questões das tarefas com maior detalhe do que fez no relatório escrito, descreve melhor a applet que implementou para a tarefa 2 do projeto e apresenta diversas simulações da série de Taylor que evidenciam a evolução do erro em função da ordem do polinómio e do centro da série. Este grupo de alunos apresentou explicações e conexões do ciclo de Otto à dinâmica térmica no movimento do pistão que não referenciaram no seu relatório escrito (Figura 20).

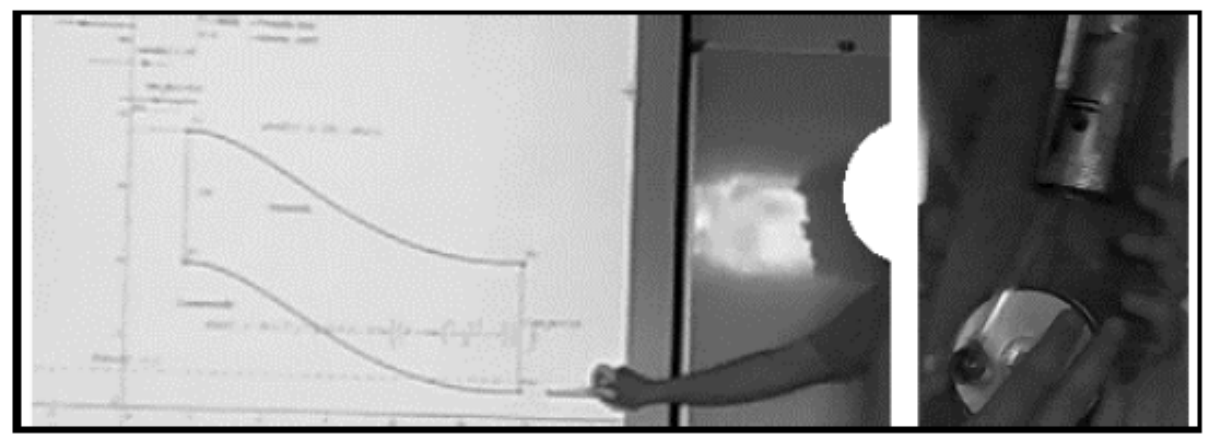

Figura 20: Explicação do ciclo de Otto na apresentação pública de um grupo de alunos (G2) de LEM.

Estes alunos referiram que "a gasolina entra durante a fase da expansão do movimento do pistão, depois após a compressão dá-se a explosão e aqui (Figura 20) a temperatura desce bruscamente que é a fase do escape dos gases...". A explicação dada por este grupo revela alguma pesquisa sobre a dinâmica do funcionamento físico do pistão em função do seu ciclo de Otto. Já em termos de comentários finais, este grupo afirma,

Foi um trabalho extenso, não foi fácil, mas sem dúvida que foi positiva a sua realização porque será útil para compreender conceitos nas outras unidades curriculares. Na matemática passamos a compreender melhor os integrais definidos e, no futuro, a resolução de integrais será mais fácil (...) após a realização do projeto tornou-se mais fácil aprender a trabalhar com o GeoGebra que necessita de algum tempo e vai-se evoluindo conforme se vai manipulando o mesmo.

As apresentações públicas realizadas pelos alunos, genericamente, permitiram que estes complementassem as suas respostas e dessem as explicações sobre aspetos da realização da tarefa de projeto e que não tinham referido no relatório escrito que entregaram anteriormente.

5.3 Perceções dos alunos de LESEE e de LEM sobre a realização do projeto 
Para averiguar o contributo da PBL na sua aprendizagem, os alunos foram interpelados numa entrevista a pronunciarem-se sobre as atividades que desenvolveram na resposta ao projeto e em particular como estas contribuem para a suas aprendizagens. A generalidade dos alunos LESEE inicia a entrevista contextualizando a interdisciplinar e multidisciplinar do projeto, como afirma um aluno do grupo 1 (G1) de entrevistados:

Realizamos um projeto sobre o tema do pêndulo nas UC's de MTENG, LMAT1 e MATE1 onde tínhamos que simular o movimento do pêndulo, a construção de código em Geogebra do movimento para uma bola e depois expandir para diversas bolas. Na construção do Software permitia-se alterar diversos parâmetros da simulação, tais como o tempo de simulação e a amplitude inicial do lançamento do pêndulo. Foi um trabalho "espetacular". Construímos um simulador acerca da teoria física do pêndulo e a construção de uma maquete para que pudéssemos comparar a situação real com a da simulação. Depois fizemos uma apresentação pública para colegas e professores dos resultados do nosso projeto.

No discurso desse aluno constata-se que a realização da tarefa de projeto foi-lhe motivante. O mesmo refere um outro aluno (G7), "Este ano aprendemos matemática de uma forma diferente do ensino secundário ... Aqui, na faculdade, conseguimos ter um contacto mais próximo com o professor, o que é cativante". Para além desse fator motivante, os alunos referiram que a realização das tarefas do projeto Ihes permitiu compreender melhor o significado da escrita formal da matemática:

O trabalho curricular de projeto foi bom para a formação dos nossos conhecimentos e que permitiu fazer uma interligação dos conteúdos de diversas disciplinas. Neste projeto, o facto de realizarmos algo físico levou-nos a perceber melhor o que estávamos a escrever e, com isso, aprender simultaneamente Matemática e Física... (G7)

Durante a entrevista, a generalidade dos alunos de LESEE reconheceu que a realização do projeto contribui-Ihes para aquisição de um conjunto competências relacionadas com a aprendizagem de tópicos de matemática, simulação matemática, conceitos de física, organização de projetos, realização de relatórios e apresentações públicas, como se observa no seguinte comentário de um aluno (G7),

Neste projeto tínhamos que planear o que iriamos fazer ao longo da sua resolução e com isso aprendemos sobretudo competências de planeamento de projetos. Na nossa atividade de resolução da tarefa tivemos que fazer simulações em Geogebra e que estavam relacionadas com competências que aprendemos na unidade curricular de Laboratórios de Matemática I. O projeto envolveu diversas componentes de cálculo da UC de Matemática I e as componentes da área de conhecimento da Física eram essencialmente matemática... O projeto contribuiu para a nossa aprendizagem da UC de Física, ajudou-nos a compreender melhor as formulas da física. Permitiunos apreender a trabalhar melhor com o Geogebra, porque nas aulas não o manipulávamos tão profundamente. Toda a gente que realizou o projeto passou a perceber mais de Geogebra... 
Alguns alunos especificaram, ainda, com mais pormenor o contributo da realização do projeto na aquisição dessas competências como se transcreve de seguida.

Como o projeto envolvia a série de Taylor, isso ajudou-nos na compreensão deste assunto, nomeadamente a construção da applet foi útil para a resposta às questões do projeto e compreender quantos mais termos usássemos no polinómio melhor seria a aproximação de Taylor à função apresentada. (G3)

... Esta forma de "provar" de forma prática (refere-se a simular) um conceito teórico permitiu-nos compreender melhor esses assuntos, ajudou-nos nas avaliações de LMAT1 e passei a resolver melhor analiticamente as séries de Taylor. (G1)

... conseguimos analisar melhor os erros de aproximação das séries em função do número de termos usados na série de Taylor... (G4)

... Este trabalho envolveu matemática, física, planeamento, gestão e simulação. Foi um trabalho diferente do que estávamos habituados até entrarmos na faculdade... Foi preciso pensar de forma diferente, a organizarmos-mos e a gerir o trabalho de modo diferente ao que estávamos habituados. Tínhamos que trabalhar em grupo, apreender a realizar relatórios, porque os professores de MTENG eram muito rigorosos na forma como escrevíamos. Aprendemos a fazer apresentações em público dos resultados do projeto, neste caso aos colegas e professores.

MTENG ajudou-nos na gestão da distribuição de tarefas de tarefas pelos elementos do grupo, gerir melhor o tempo, a estrutura do relatório, a preparar a presentação pública, as técnicas de apresentação e a organização dos Powerpoint... Com a realização do projeto aprendemos como a matemática se aplica a problemas da vida real. (G6)

... O projeto permitiu-nos apreender a trabalhar melhor com o Geogebra e a realizar relatórios. Foi o nosso primeiro relatório da Faculdade com um nível de elaboração tão elevada e segundo as normas impostas neste tipo de trabalho (refere-se à APA). (G2)

$\mathrm{Na}$ entrevista, os alunos consideram que a realização da tarefa de projeto lhes contribuiu para uma melhor aprendizagem em unidades curriculares específicas do seu curso e, ainda, sugerem que em futuros projeto se incluam temas mais específicos da engenharia eletrotécnica, como mostra os seguintes comentários de um dos alunos.

Embora o projeto tenha funcionado bem, achamos que futuramente o tema a abordar no projeto deva ser na área da Eletrotecnia ... Este projeto foi útil para a nossa aprendizagem em MATE1 mas, também, na UC de TEOEL (Teoria da Eletricidade) onde se trabalha muito o conceito de funções sinusoidais. Esse conceito é muito semelhante ao que aparece no movimento do pêndulo, porque se trata de um movimento oscilatório. O projeto ajudou-nos na compreensão da trigonometria que é necessário para o conhecimento da Eletrotecnia. (G3)

Durante a entrevista a maioria dos alunos do curso de LEM começa por enquadrar o contexto do projeto, por exemplo, um aluno (G4) como relata: 
No projeto tivemos que responder a diferentes tarefas sobre diversas aplicações de conteúdos matemáticos de MATE1... No projeto tínhamos que "demonstrar" com o Geogebra a aplicação da matemática a casos práticos da nossa vida real, em particular, o pistão de um motor de um automóvel. O projeto incluía a realização de 3 tarefas de aplicação prática de conteúdos de MATE1 apoiadas no Geogebra e com prazos diferentes de entrega. Ou seja, era por em prática o que aprendíamos nas aulas. Incluiu a simulação do movimento de um pistão, aprendizagem de trigonometria, as séries de Taylor e os integrais definidos aplicados a modelos físicos.

Este enquadramento foi ainda complementado por outro aluno (G7):

A realização do projeto envolvia uso do Geogebra, aplicação da matemática a um problema físico, o pistão do motor de um automóvel. Tínhamos que analisar o movimento do pistão, analisar gráficos em função da alteração de parâmetros de simulação, tais como, comprimento do braço do pistão ou a frequência da sua rotação. Tivemos que construir um protótipo do pistão, realizar um relatório final e um vídeo com a minha apresentação de resultados do projeto, porque não pode estar presente no dia da apresentação pública.

$\mathrm{Na}$ entrevista, a maioria dos alunos de LEM indicaram que tiveram dificuldades iniciais em trabalhar com o GeoGebra, mas que foram colmatadas ao longo do projeto, como se pode constatar nas afirmações de dois alunos:

Inicialmente tivemos algumas dificuldades em realizar o projeto, porque não sabíamos trabalhar bem com o Geogebra. Com a ajuda do professor conseguimos ultrapassar essas dificuldades. Já em ralação à parte de matemática formal de resposta às tarefas não tivemos grandes de dificuldades. Este projeto contribuiu para a nossa aprendizagem, conseguimos ver onde a matemática pode ser aplicada... Permitiu melhorar a nossa capacidade de interpretar gráficos resultantes das diversas simulações. (G7)

O grau de dificuldade do projeto foi elevado, principalmente trabalhar com o Geogebra porque não estávamos muito habituados a usá-lo. Pensamos que realização do projeto nos será útil para o futuro e contribuiu para nossa aprendizagem em todos os conteúdos de MATE1, porque obrigava-nos a estar sempre a par com matéria lecionada nas aulas. A 1a tarefa permitiu-nos aprofundar a nossa aprendizagem no cálculo diferencial, as séries de Taylor na $2 \underline{a}$ tarefa e os integrais na 3 a tarefa. (G1)

Nos comentários desses dois alunos foi percetível que a realização do projeto lhes contributo para a aprendizagem dos conteúdos matemáticos de MATE1, tal como foi proferido por outros alunos:

O projeto contribuiu para a nossa aprendizagem. Por exemplo, a última tarefa do projeto fui fundamental para nossa aprendizagem em integrais através do cálculo das áreas envolvidas no problema... (G2) 
O projeto teve diversas etapas de resolução conforme eram lecionados os respetivos conteúdos matemáticos em MATE1 necessários à solução da tarefa... Por vezes, tínhamos de fazer demonstrações/provas matemáticas, interpretações de assuntos que eram colocados nas tarefas e que eram diferentes do que estávamos habituados na matemática. (G5)

Para além das competências matemáticas, durante a entrevista, a maioria dos alunos do curso de LEM referem ainda que aprenderam conceitos específicos relacionados com o pistão do motor de um automóvel, como se constata na seguinte afirmação de um aluno (G5):

A teoria matemática que aprendemos foi aplicada à construção do software de simulação. Com isso, nós conseguimos determinar séries de Taylor, determinar o volume de combustível no interior do pistão com integrais definidos. Conseguimos compreender o movimento de um pistão e como se fazia a combustão do fluido no seu interior. Percebemos na teoria e na prática a mecânica do seu funcionamento. Neste projeto, o estudo do pistão esteve sempre ligado à matemática. (G5)

Com a realização do projeto, a generalidade dos alunos de LEM disseram que melhoraram a sua compreensão dos conteúdos matemáticos de MATE1, do funcionamento do Pistão e do Geogebra. Em particular, em relação a este software referem "O uso das tecnologias na matemática é vantajoso porque permite-nos associar a matemática à vida real. O Geogebra permite simular o movimento de objetos físicos e é um bom software para realizar gráficos" (G3).

\section{CONCLUSÕES}

O conhecimento matemático é um requisito fundamental para a aprendizagem dos alunos nas unidades curriculares dos cursos de engenharia. É essencial que sejam criadas condições e ambientes de aprendizagem que conduzam os alunos a uma aprendizagem matemática com compreensão e vocacionada para as características próprias do ensino da engenharia (Crawley, Malmqvist, Östlund \& Brodeu, 2007). O projeto é por excelência uma tarefa que permite integrar competências transversais multidisciplinares -- Matemática, Física e Engenharia -- de trabalho em contexto social (equipa). Permite que os alunos adquiram capacidade de gestão de projetos e de relações interpessoais, de comunicação através da elaboração de relatórios escritos e da apresentação pública de resultados (Lehmann, Christensen , Du \& Thrane, 2008; López, García \& et. al., 2017). Todas estas competências convergem com as normas do modelo CDIO (Malmqvist, 2009) e que são essenciais para um engenheiro. Com a tarefa de projeto, os alunos realizaram atividades matemáticas relacionadas com a modelação matemática (Biembengut \& Hein, 2000) e simulação de processos físicos que podem contribuir para reforçar uma aprendizagem matemática com mais significado. Essas tarefas incluem atividades de dedução matemática para construir modelos matemáticos representativos do sistema físico (Biembengut \& Hein, 2000). A tarefa de projeto promoveu a construção do conhecimento matemático e físico relacionado com o tema do projeto, como é defendido nas normas CDIO (Crawley et al., 2007; Malmqvist, 2009) e dos 'outcomes' do EUR-ACE (Malmqvist, 2009). A maioria de competências transversais enunciadas foram reconhecidas pelos alunos, particularmente os do curso de LESEE, tais como a gestão do 
projeto, a elaboração do relatório final e a comunicação oral de resultados. Este facto é consequência de o projeto ter envolvido outras unidades curriculares que reforçassem essas componentes transversais e que são importantes, como relatam outros estudos (Alves \& et. al, 2016, Lima, 2012; López, García \& et. al., 2017). Já os alunos de LEM tiveram mais dificuldades com a gestão do projeto, a elaboração do relatório final e a comunicação oral de resultados. Este facto é consequência de o projeto não ter envolvido outras unidades; curriculares que reforçassem essas componentes transversais e que são importantes.

Com a realização desta tarefa de projeto, os alunos destacam a consolidação de conhecimentos sobre os tópicos estudados, em particular a série de Taylor, e de conhecimentos de Física. Os alunos de LEM e LESEE exploraram por simulação, visual e analiticamente, os conceitos relacionados com a série de Taylor através da applet que criaram no projeto e isso contribuiu para o esclarecimento e a compreensão de conceitos ligados às séries, nomeadamente relacionaram o erro de aproximação de um polinómio de Taylor de uma função com a ordem do polinómio ou com o seu centro de convergência. Os alunos de LESEE reconhecem que este tipo de tarefas de aprendizagem baseada em projetos lhes traz uma motivação adicional pelo facto de estar integrado e interligado com diversas unidades curriculares, como referem também Lima (2012) e López, García e outros (2017). O fator motivação deriva da inclusão de contextos reais físicos, de ser uma atividade prática de desenvolvimento de simuladores em software e de protótipos reais, realizada cooperativamente entre os elementos do grupo. Os alunos identificaram que as atividades que desenvolveram durante a realização do projeto contribuíram para a aquisição de competências que lhes serão úteis no seu futuro profissional, de forma semelhante com os resultados alcançados por López, García e outros (2017).

Os resultados deste estudo sugerem que estes projetos tenham um caráter interdisciplinar (Masson et al., 2012) no sentido de ter uma maior aplicabilidade, criem uma maior motivação e não impliquem uma carga adicional de tarefas extra-aula, como refere também no seu estudo Alves e outros (2016). A existência de unidades curriculares do tipo Laboratórios de Matemática potencia a facilidade dos alunos em usar os softwares matemáticos e torna-os não tão intrusivos nas aulas de Matemática.

\section{REFERÊNCIAS}

Alves, A., Sousa, R. \& al. (2016). Teacher's experiences in PBL: implications for practice, European Journal of Engineering Education, 41:2, 123-141, DOI: 10.1080/03043797.2015.1023782.

Bassanezi, R. (2002). Ensino - aprendizagem com Modelagem matemática. 3a Edição Publisher Editora Contexto Editor Jaime Pinsky. ISBN85-7244-207-3. https://www.researchgate.net/publication/256007243_Ensino__aprendizagem_com_Modelagem_matematica

Bellemain, F., Bellemain, P. \& Gitirana, V. (2006). Simulação no ensino da matemática: um exemplo com Cabri-Géomètre para abordar os conceitos de área e perímetro. In III 
Seminário Internacional de Pesquisa em Educação Matemática. Águas de Lindóia - São Paulo 11 a 14 de outubro de 2006.

Biembengut, M. \& Hein, N. (2000). Modelagem Matemática no Ensino. São Paulo: Editora Contexto.

Blomhoj, M. (2009). Different perspectives in research on the teaching and learning mathematical modeling. In M. Blomhoj \& S. Carreira (Eds.), Mathematical applications and modeling in the teaching and learning of mathematics (pp. 5-21). Roskilde, Denmark: Roskilde University.

Blum, W. (2002). ICMI Study 14: Applications and modelling in mathematics education Discussion document. Educational Studies in Mathematics, 51(1-2), 149-171.

Bogdan, R. \& Biklen, S. (1994). Investigação Qualitativa em Educação. Porto: Porto Editora.

Bornatto, G. (2002). Modelagem- Simulação - Informática e a Matemática. Rev. PEC, Curitiba, 2(1), 67-71.

Cai, J., Michelle, G. \& al. (2014) Mathematical modeling in school education: mathematical, cognitive, curricular, instructional and teacher education perspectives. In P. Liljedahl, C. Nicol, S. Oesterle, \& D. Allan (Eds.), Proceedings of the Joint Meeting of PME 38 and PME-NA 36, PME-NA, Vancouver, Canada, pp. 145-172.

Crawley, E. \& al. (2007). Rethinking engineering education the CDIO approach. Springer Science+Business Media, LLC. New York, USA. ISBN 978-0-387-38287-6.

Crawley, E., Edström, K., Malmqvist, J. \& al. (2005). Curriculum Design Based on the CDIO Model. Proceedings of the 2005 international SEFI conference, Ankara, Turkey.

Crawley, E., Malmqvist, J., Lucas, W. \& Brodeur, D. (2011). The CDIO Syllabus v2.0. An Updated Statement of Goals for Engineering Education. Proceedings of the 7th international CDIO conference, Technical University of Denmark, Copenhagen, June 20-23.

Croft, A. \& Davison, R. (2004). Mathematics for engineers: a modern interactive approach. 2nd edition. Pearson Education, Prentice Hall. ISBN 13: 978-0-13-120193-x.

Edström, K. \& Kolmos, A. (2014) PBL and CDIO: complementary models for engineering education development. European Journal of Engineering Education, 39:5, 539-555. DOI: 10.1080/03043797.2014.895703.

Ferreira, E., Nicola, S. \& Figueiredo, I. (2011). Peer instruction method in introductory math courses. In Proceedings of the 7th International CDIO Conference, Technical University of Denmark, Copenhagen, June 20 - 23, 2011.

Galbraith, P., Stillman, G., Brown, J., \& Edwards, I. (2007). Facilitating middle secondary modeling competencies, In C. Haines, P. Galbraith, W. Blum \& S. Khan (Eds.), Mathematical modeling (ICTMA 12): Education, engineering and economics (pp. 130-140). Chichester, England: Horwood. 
Graaff, E., \& Kolmos, A. (2003). Characteristics of Problem-based Learning. International Journal of Engineering Education 19 (5): 657-662.

Hennessy, S., Wishart, J. \& al. (2007). Pedagogical approaches for technology-integrated science teaching. Computers \& Education, 48(1), 137-152

Jurewitsch, B. (2012). A Meta-Analytic and Qualitative Review of Online Versus Face-to-face Problem-Based Learning. Journal of Distance Education (Online), 26 (2).

Kolmos, A., \& de Graaff, E. (2014). Problem-Based and Project-Based Learning in Engineering Education: Merging Models. In A. Johri, \& B. M. Olds (Eds.), Cambridge Handbook of Engineering Education Research (pp. 141-161). Cambridge University Press. DOI: 10.1017/CBO9781139013451.012.

Lehmann, M., Christensen, P., Du, X. \& Thrane, M. (2008). Problem-oriented and project-based learning (POPBL) as an innovative learning strategy for sustainable development in engineering education. European Journal of Engineering Education, 33:3, 283-295. DOI: 10.1080/03043790802088566

Lima, R. (2012). Aprendizagem baseada em projectos interdisciplinares: Conceitos, implementação e resultados. In XVII ENCEP 2012: Encontro Nacional de coordenadores de cursos de engenharia de Produção. Natal (Brasil), Maio de 2012.

López, M., García, M. \& al. (2017). Implementation of a project-based engineering school: increasing student motivation and relevant learning. European Journal of Engineering Education, 42:6, 618-631, DOI: 10.1080/03043797.2016.1209462.

Malmqvist, J. (2009). A comparison of the CDIO ANDEUR-ACE quality assurance systems. In Proceedings of the 5th International CDIO Conference, Singapore Polytechnic, June 7-10.

Masson, T. \& al. (2012). Metodologia de ensino: Aprendizagem baseada em projetos (PBL). In XL Congresso Brasileiro de Educação em Engenharia. 3 a 6 de Setembro de 2012. Belém PA.

Rutten, N. (2014). Teaching with simulations. Tese de doutoramento. Utrecht University. Netherlands. Agosto, 2014. ISSN 1381-3617.

Takaci, Dj., \& Budinski, N. (2013). Using Computers and Context in the Modeling-Based Teaching of Logarithms. Computers in the Schools, 30:1-2, 30-47, DOI:10.1080/07380569.2013.764275.

Trundle, K., \& Bell, R. (2010). The use of a computer simulation to promote conceptual change: $A$ quasi-experimental study. Computers \& Education, 54(4), 1078-1088

Zuffi, E. \& Onuchic, R. (2007). O ensino-aprendizagem de matemática através da resolução de problemas e os processos cognitivos. UNION- Revista Iberoamericana de Educación Matemática, 11, 79-97. 